Universidade de São Paulo

Escola Superior de Agricultura "Luiz de Queiroz"

Retenção da água em Latossolo cultivado sob plantio direto por longo período

\title{
Gabriela Hellmeister
}

Dissertação apresentada para obtenção do título de Mestra em Ciências. Área de concentração: Solos e Nutrição de Plantas

Piracicaba

2020 


\section{Gabriela Hellmeister}

Engenheira Agrônoma

Retenção da água em Latossolo cultivado sob plantio direto por longo período

Orientador:

Prof. Dr. PAULO LEONEL LIBARDI

Dissertação apresentada para obtenção do título de Mestra em Ciências. Área de concentração: Solos e Nutrição de Plantas 
Dados Internacionais de Catalogação na Publicação DIVISÃO DE BIBLIOTECA - DIBD/ESALQ/USP

\section{Hellmeister, Gabriela}

Retenção da água em Latossolo cultivado sob plantio direto por longo período / Gabriela Hellmeister. - - Piracicaba, 2020.

$74 \mathrm{p}$.

Dissertação (Mestrado) - - USP / Escola Superior de Agricultura "Luiz de Queiroz".

1. Curva de retenção 2. Distribuição de poros 3. Manejo do solo I. Título 
Dedico esta dissertação aos meus pais, Carmen Francisca Lourenço Pinto Hellmeister e Luiz Antônio Vasques Hellmeister.

Ofereço a todos aqueles que possam se interessar pelo assunto desta dissertação. 
"To speak impartially, the best men that I know are not serene, a world in themselves. For the most part, they dwell in forms, and flatter and study effect only more finely than the rest. We select granite for the underpinning of our houses and barns; we build fences of stone; but we do not ourselves rest on an underpinning of granitic truth, the lowest primitive rock. Our sills are rotten. What stuff is the man made of who is not coexistent in our thought with the purest and subtilest truth? I often accuse my finest acquaintances of an immense frivolity; for, while there are manners and compliments we do not meet, we do not teach one another the lessons of honesty and sincerity that the brutes do or of steadiness and solidity that the rocks do. The fault is commonly mutual, however; for we do not habitually demand any more of each other."

\section{David Henry Thoreau}

Life without principle (p.8) 


\section{AGRADECIMENTOS}

Primeiramente agradeço a Deus, e a meus pais Carmen e Luiz pelo apoio incondicional de sempre e esforços desmedidos para que a realização de mais esta etapa fosse concluída com êxito. Sou grata sobretudo pelo exemplo de amor, bondade, fé e compreensão.

Agradeço ao Professor Libardi pela orientação e pela amizade também cultivada ao longo deste período, no qual o crescimento não foi somente acadêmico, pois através da convivência aprendemos por seu exemplo a perseverança e a humildade.

Agradeço a toda a minha família que desde o começo da jornada torceu por mim, estando sempre ao meu lado com palavras de carinho e suporte sempre que necessário, à minha irmã Marília, ao meu irmão Victor, Ana e Luciane. Agradeço também a todos os que tive prazer de conviver enquanto estive em São Carlos, época em que decidi fazer o mestrado, a minha tia Fátima, meus tios Antônio e Edna, meus tios-avós Leni e Eunísio (engenheiro agrônomo formado em 1956 pela ESALQ) e toda a sua família (Malagutti).

Agradeço a toda a equipe técnica da ESALQ por garantir o funcionamento correto das instalações e dependências como laboratórios, e outras instalações. Em especial ao Francisco Bernardo Dias e Reginaldo Natalino Nogueira pelo companheirismo e amizade, além dos trabalhos de campo e de laboratório.

Agradeço a todos os meus colegas de orientação, sem os quais meu desenvolvimento científico não teria sido completo. À Aline Martineli Batista pela grande ajuda com as dúvidas em estatística, à Camila Cassante de Lima pelo auxílio imprescindível em ceder sua área de experimento na fazenda Santa Elisa no IAC (Instituto Agronômico de Campinas), ao Cezar Augusto Medeiros Rebouças pela pronta disposição em auxiliar na formatação, ao Ismael Meurer pelo suporte em informática e outras questões técnicas, à Maria Laiane do Nascimento Silva, Thaís Nascimento Pessoa, Tamires Teles de Souza pelo auxílio constante às questões acadêmicas, bem como as burocráticas. Finalmente, a cada um pela convivência e ajuda com as dúvidas constantes que surgiram ao longo deste caminho e, claro, pelas boas risadas e conversas durante os momentos de descontração (cafézinho).

Agradeço a todos os amigos das boas horas, os novos e os de outrora, incluindo aqueles com quem eu dividi um teto: Thalita, Angélica, Luana, Bárbara, Matheus, Thaís, Rodolfo, Stéfani (Mijoleta), Mayara (Siésai), Beatriz (Bunda), Lounan (Meidin), Mayra (Ariadna), Henrique (Pena), Maria Beatriz (Hadouken), Lucas (Borra Botas), Gabriela (Saponga), Franciele (Azaléia), Amanda 
(Xicória), Larissa (Fetixe), e ainda aos meus amigos de Bauru, Thais Michelão, Victor Solci e Marcos Scarpim, enfim, todos que tive a felicidade dos encontros e dos reencontros ao longo desses dois anos, afinal, esses momentos são tão importantes quanto os de estudo.

Agradeço ao meu namorado Xavier Le Gallic por todo apoio, companheirismo e cumplicidade, e mesmo com a distância, sempre se fez presente através de seu carinho e dedicação.

Agradeço também a todos os professores e pesquisadores com os quais tive a satisfação de trabalhar anteriormente e que me influenciaram a escolher a área acadêmica, pelo incentivo à pesquisa e desenvolvimento de projetos anteriores, aos professores da UNESP Botucatu: Kléber Lanças, professor Paulinho Arbex, Ciro Rosolém, e ao professor e pesquisador da EMBRAPA instrumentação Silvio Crestana.

Agradeço, finalmente, ao $\mathrm{CNPq}$ pela bolsa concedida para a realização deste projeto. (Processo: 131712/2018-7). 


\section{SUMÁRIO}

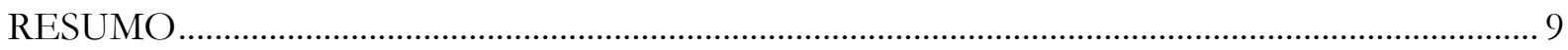

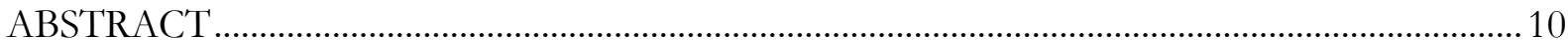

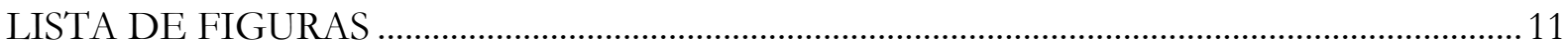

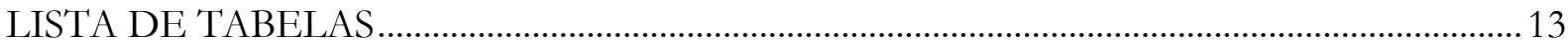

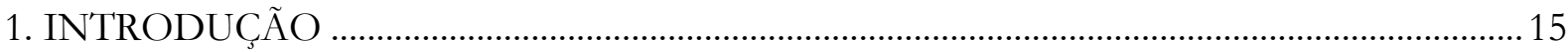

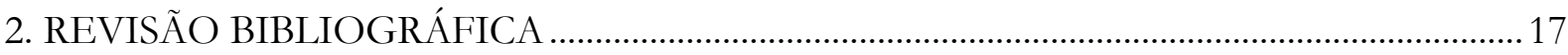

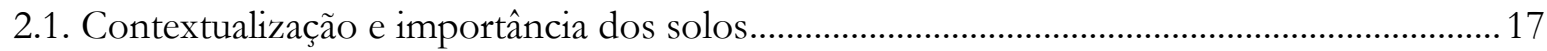

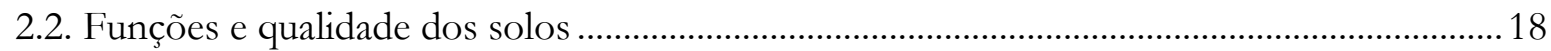

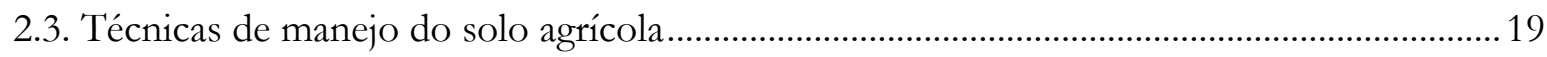

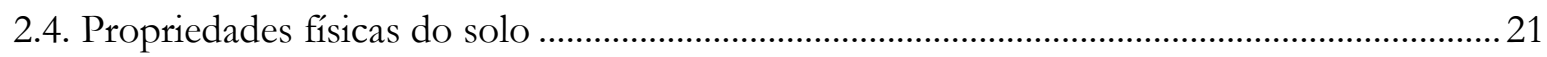

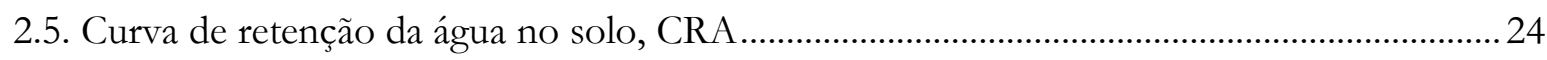

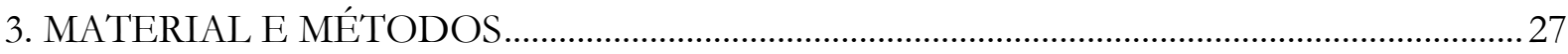

3.1. Localização e caracterização da área experimental...................................................................2 27

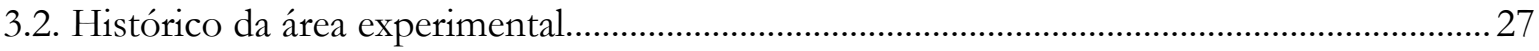

3.3. Delineamento experimental e caracterização dos tratamentos ...................................................2 29

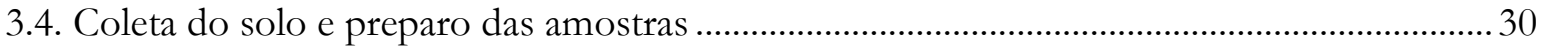

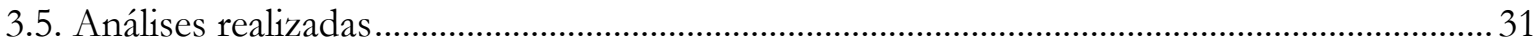

3.6. Propriedades físicas estimadas a partir da CRA ajustada ……………………………............... 41

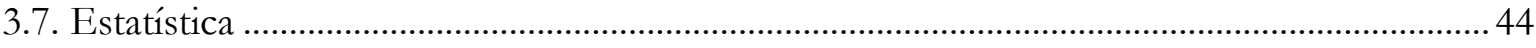

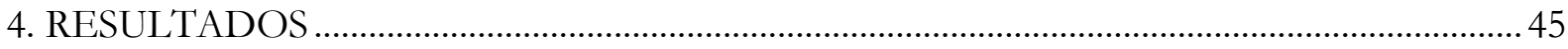

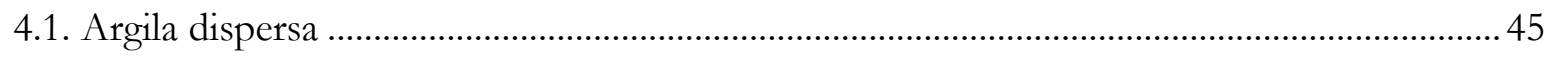

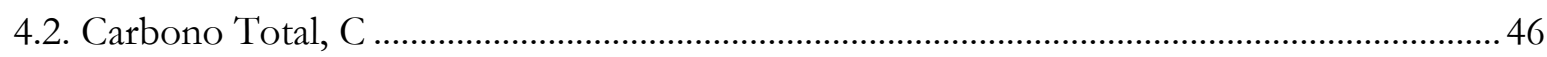

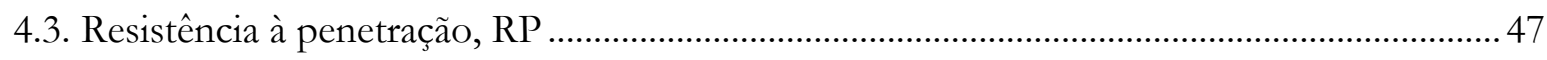

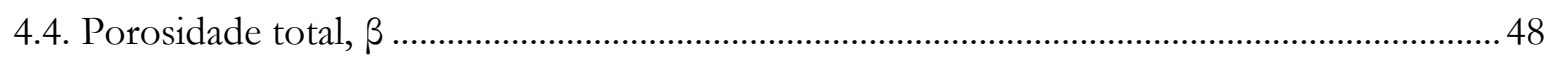

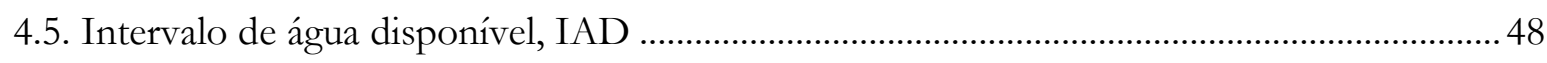

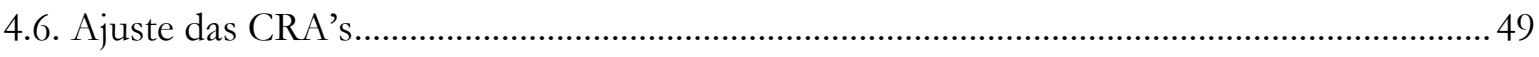

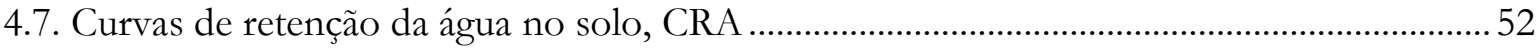

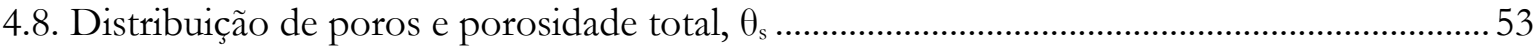

4.9. Curvas da frequência de raios dos poros ................................................................................... 54

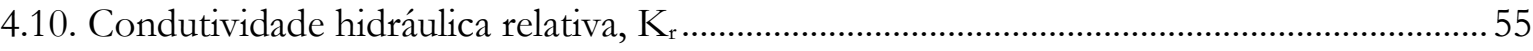

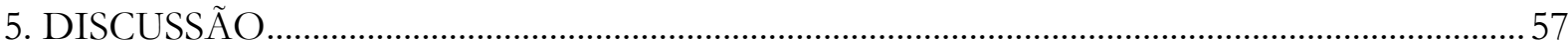

6. CONCLUSÃO 
7. CONSIDERAÇÕES FINAIS 65

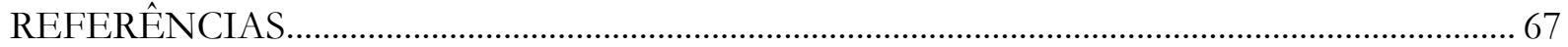




\section{RESUMO}

\section{Retenção da água em Latossolo cultivado sob plantio direto por longo período}

Os solos utilizados na agricultura sofrem, invariavelmente, modificações de suas propriedades originais pelo seu manejo. O sistema de plantio direto, PD, é indicado com o intuito de proteger o solo, promovendo uma melhora dos atributos físicos, químicos e biológicos do solo. Porém, alguns solos sob PD apresentam maior densidade devido ao seu não revolvimento. Diante deste panorama, objetivou-se avaliar, pelo estudo da curva de retenção da água no solo (CRA), algumas propriedades fisico-hídricas do solo, buscando subsídios para entender como a utilização do PD por longo período de tempo pode influenciar o comportamento da água, no que diz respeito a sua retenção e condução em um Latossolo brasileiro, em comparação ao plantio convencional, PC. O Latossolo da área deste estudo vem sendo cultivado sob PD há cerca de 12 anos com rotação de diferentes culturas agrícolas de inverno e verão. O delineamento experimental possui três blocos casualizados com parcelas subdivididas, sendo o fator da parcela o manejo do solo (Plantio Direto - PD e Preparo Convencional - PC) e o fator da subparcela três tipos de cobertura do solo (Gramínea, Leguminosa e sem cobertura - Pousio) para as camadas de solo 0-0,5m;0,5-0,10m;0,10-0,20m e 0,20-0,30m de profundidade. Foram realizadas caracterização textural e análises para Carbono Total (C), Resistência a Penetração (RP), Argila Pontamente e Mecanicamente Dispersa em Água (APDA e AMDA), além da determinação das CRA's que foram utilizadas para avaliar a distribuição do tamanho de poros do solo, e aplicar o modelo de van Genutchen de estimativa da condutividade hidráulica relativa $(\mathrm{Kr})$. Pelos resultados pode-se concluir que as CRA's indicaram um maior intervalo de água disponível para a cobertura gramínea, mas na comparação entre PD e PC este índice foi maior no PC.

Palavras-chave: Curva de retenção, Distribuição de poros, Manejo do solo 


\section{ABSTRACT \\ Water retention in Oxisol under no-tillage for long period}

Soils used in agriculture invariably undergo changes in their original properties due to the management practices. The no-tillage management, PD, is used to protect the soil, promoting improvement in the physical, chemical and biological soil attributes. However, there are soils under PD that have a higher bulk density due to the no plowing operations. Therefore, the objective of this work was to evaluate from the soil water retention curves (CRA) determination, some soil physical-hydric properties, seeking subsidies to understand how the use of PD for a long period can influence the water behavior, with respect to its retention and conduction in a Oxisol, compared to conventional management, PC. The Oxisol in the area of this study has been cultivated under PD for about 12 years with rotation of different winter-summer crops. The experimental design has three randomized blocks with subdivided plots, the plot factor being soil management (no-tillage - PD and conventional tillage - PC) and the subplot factor, the three types of cover crops (Grass, Leguminous and without cover - Fallow), to the depths of $0-0.5 \mathrm{~m} ; 0.5-0.10 \mathrm{~m}$; $0.10-0.20 \mathrm{~m} ; 0.20-0.30 \mathrm{~m}$. Textural characterization and analyzes were carried out for Total Carbon (C), Penetration Resistance (RP), Readly and Mechanically Dispersible Clay in Water (APDA and AMDA), in addition to the determination of the CRA's which was used to evaluate the pore size distribution, and to apply the van Genutchen model, relative hydraulic conductivity $(\mathrm{Kr})$ of stimation. From the results it can be concluded that PC retention curves indicated greater water retention by the soil whose most relevant factor was the type of cover crop used.

Keywords: Soil-water retention curve, Pore-size distribution, Soil management 


\section{LISTA DE FIGURAS}

Figura 1. Estação Experimental Central do Instituto Agronômico de Campinas (Fazenda Santa Elisa) 27

Figura 2. Croqui da área experimental.

Figura 3. Coleta e preparo das amostras de solo. 31

Figura 4. Análise laboratorial para densidade de partículas do solo. .32

Figura 5. Processo da caracterização granulométrica. .33

Figura 6. Processos para análise de APDA e AMDA. .34

Figura 7. Penetrômetro de bancada. 38

Figura 8. Processo de obtenção das CRA's em laboratório. 41

Figura 9. Teor médio de Argila Prontamente Dispersa em Água, APDA, para as profundidades avaliadas. Letras comparam e demonstram as diferenças dos valores apresentados para o fator significante, determinado pelo teste Tukey a $5 \%$

Figura 10. Teores médias de Argila Mecanicamente Dispersa em Água, AMDA, para os manejos avaliados (PC e PD). Letras comparam e demonstram as diferenças dos valores apresentados para o fator significante, determinado pelo teste Tukey a 5\%. .46

Figura 11. Teor médio de Argila Mecanicamente Dispersa em Água, AMDA, para as profundidades avaliadas $(0,00-0,05 \mathrm{~m} ; 0,05-0,10 \mathrm{~m} ; 0,10-0,20 \mathrm{~m}$; e $0,20-0,30 \mathrm{~m})$. Letras comparam e demonstram as diferenças dos valores apresentados para o fator significante, determinado pelo teste Tukey a $5 \%$ .46

Figura 12. Teor médio de carbono, C, para as coberturas avaliadas (gramínea, leguminosa e pousio) em ambos os manejos (PD e PC). Letras minúsculas comparam os manejos dentro de cada cobertura e letras maiúsculas comparam as coberturas dentro de cada manejo pelo teste de Tukey ao nível de 5\% de significância.

Figura 13. Teor médio de Resistência à penetração média, RP, para as coberturas avaliadas (gramínea, leguminosa e pousio) em ambos os manejos (PD e PC). Letras minúsculas comparam os manejos dentro de cada cobertura e letras maiúsculas comparam as coberturas dentro de cada manejo pelo teste de Tukey ao nível de 5\% de significância.

Figura 14. Porosidade total médio para as coberturas avaliadas (gramínea, leguminosa e pousio). Letras comparam e demonstram as diferenças dos valores apresentados para o fator significante, determinado pelo teste Tukey a $5 \%$ 
Figura 15. Teor médio de intervalo de água disponível, IAD, para os manejos avaliados (PC e PD). Letras comparam e demonstram as diferenças dos valores apresentados para o fator significante, determinado pelo teste Tukey a 5\%.

Figura 16. IAD para as coberturas avaliadas (gramínea, leguminosa e pousio). Letras comparam e demonstram as diferenças dos valores apresentados para o fator significante,

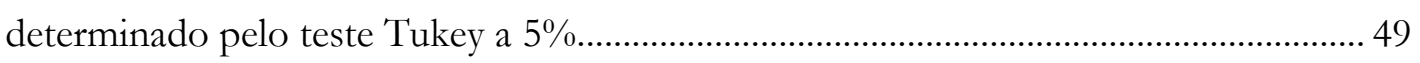

Figura 17. Curvas de Retenção de Água no Solo, CRA's, obtidas pelo ajuste da equação (6)....... 52

Figura 18. Distribuição de poros (macro, micro e macroporos) e porosidade total $\left(\theta_{\mathrm{s}}\right)$................. 53

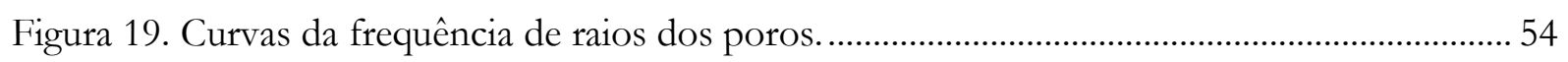

Figura 20. Gráficos da função condutividade hidráulica relativa do solo $K_{\mathrm{r}}(\theta)$.............................. 55 


\section{LISTA DE TABELAS}

Tabela 1. Histórico de plantio da área experimental.

Tabela 2. Frações granulométricas e densidade das partículas das amostras compostas para cada profundidade.

Tabela 3. Argila prontamente dispersa em água, APDA, para os dois tipos de cultivo (plantio direto e convencional), para as três coberturas (gramínea, leguminosa e pousio), nas quatro profundidades do solo $(0,00-0,05 \mathrm{~m} ; 0,05-0,10 \mathrm{~m} ; 0,10-0,20 \mathrm{~m} ; 0,20-0,30 \mathrm{~m}) \ldots . . .35$

Tabela 4. Argila mecanicamente dispersa em água, AMDA, para os dois tipos de cultivo (plantio direto e convencional), para as três coberturas (gramínea, leguminosa e pousio), nas quatro profundidades do solo $(0,00-0,05 \mathrm{~m} ; 0,05-0,10 \mathrm{~m} ; 0,10-0,20 \mathrm{~m} ; 0,20-0,30 \mathrm{~m}) \ldots . . .35$

Tabela 5. Carbono orgânico total, C, para os dois tipos de cultivo (plantio direto e convencional), para as três coberturas (gramínea, leguminosa e pousio), nas quatro profundidades do solo $(0,00-0,05 \mathrm{~m}$; 0,05-0,10 m; 0,10-0,20m; 0,20-0,30m)............................................... 36

Tabela 6. Densidade do solo, $\varrho$, para os dois tipos de cultivo (plantio direto e convencional), para as três coberturas (gramínea, leguminosa e pousio), nas quatro profundidades do solo (0,00-0,05m; 0,05-0,10m;0,10-0,20m;0,20-0,30m).

Tabela 7. Valores de resistência a penetração, RP, para os dois tipos de cultivo (plantio direto e convencional), para as três coberturas (gramínea, leguminosa e pousio), nas quatro profundidades do solo $(0,00-0,05 \mathrm{~m} ; 0,05-0,10 \mathrm{~m} ; 0,10-0,20 \mathrm{~m} ; 0,20-0,30 \mathrm{~m})$.................... 38

Tabela 8. Parâmetros de ajuste da equação (6) para gramínea. ……………………………................. 51

Tabela 9. Parâmetros de ajuste da equação (6) para leguminosa. .......................................................... 51

Tabela 10. Parâmetros de ajuste da equação (6) para pousio. ………………………………............... 51 


\section{INTRODUÇÃO}

O solo é um recurso natural que desempenha papel fundamental na sobrevivência de todas as espécies existentes no planeta, servindo de suporte ao desenvolvimento destas. É, portanto, objeto imprescindível de estudo e, sendo muito complexo, se faz necessário a investigação a fundo de suas características físicas, químicas, biológicas, para aprimorar e desenvolver práticas sustentáveis de uso e manejo, preservando sua funcionalidade, bem como sua qualidade (Blum, 2005; Herrick, 2000).

Os solos utilizados na agricultura sofrem, invariavelmente, modificações de suas propriedades originais pelo manejo incorreto (Bridges e Oldeman, 1999), podendo causar danos com a imposição excessiva de carga pelo uso de maquinário agrícola, resultando em perdas severas à sua estrutura, como a compactação (Pires et al., 2017) da qual decorre diminuição da aeração e poder de penetração de raízes, com a possibilidade de iniciar processos de difícil remediação como a erosão (Pimentel et al., 1995).

Existem diversos tipos de manejo utilizados na prática da agricultura, os mais comumente empregados sendo o sistema de plantio convencional, PC, e o sistema plantio direto, PD (Strudley et al., 2008). Em solos cultivados de forma intensiva, utiliza-se geralmente o PC, no qual há revolvimento do solo feito por equipamentos agrícolas pesados e que resultam em alteração das características físicas do solo (Chamen et al., 2003). Isto ocorre, principalmente, pela realização das operações de aragem e gradagem que buscam promover aeração, destorroamento e incorporação de fertilizantes ou corretivos. No entanto, estas operações quando efetuadas de maneira frequente podem ocasionar eventos erosivos, visto que desagregam a estrutura original do solo (Vanwalleghem et al., 2017). De outro modo, o PD é considerado uma prática conservacionista pois apresenta vantagens, como custo reduzido devido ao menor número de operações mecanizadas, maior armazenagem e incorporação de carbono no solo pela manutenção da palhada e maior estabilidade estrutural contra a ação das gotas de chuva, além da menor perda de herbicidas por lixiviação (Schlüter et al., 2018). A fim de reduzir efeitos negativos, como o transporte da camada superficial de solos descobertos pela ação da água, práticas conservacionistas como o uso de cobertura, restos culturais, rotação de culturas e o não revolvimento do solo, vêm sendo utilizadas desde a década de 1990 no Brasil (Bayer et al., 2000). A utilização do PD objetiva a proteção do solo, pela redução ou eliminação dos processos de erosão, diminuição das taxas de evapotranspiração, aumento da infiltração, retenção e armazenagem de água no solo. Muitos estudos demonstram que esta prática promove uma melhora dos atributos físicos, químicos e biológicos do solo (Nascente et al., 2013). No entanto, Camara e Klein (2006) demonstraram que solos sob PD 
possuem maior densidade do solo em sua camada superficial pelo fato de ser revolvida somente a linha de semeadura. Adicionalmente, a ação do tráfego de máquinas agrícolas pesadas resulta em danos severos como compactação e consequente redução do espaço poroso desta camada, responsável pela infiltração de água no solo, pela aeração e penetração das raízes das plantas cultivadas, resultando em queda de produtividade ou até mesmo a perda total da lavoura (Tormena et al., 1998).

Diante deste panorama, objetivou-se avaliar detalhadamente com este trabalho algumas propriedades fisico-hídricas do solo, buscando, assim, subsídios de como a implementação do PD utilizado por longo período de tempo pode influenciar o comportamento da água no que diz respeito a sua retenção e condução em um solo tropical cultivado e de textura muito argilosa, em comparação à utilização das técnicas de plantio convencional.

O solo da área escolhida para o desenvolvimento deste estudo é um Latossolo cultivado sob PD há cerca de 12 anos com rotação de diferentes culturas agrícolas de inverno e verão.

Acredita-se que a obtenção da curva de retenção da água no solo, CRA, a qual relaciona o conteúdo de água em massa, $\mathrm{U}$, ou em volume, $\theta$, no solo e o potencial mátrico da água, $\phi_{\mathrm{m}}$, no solo reveste-se de especial importância nesse contexto, pois por meio dela se pode obter dados relevantes sobre a disponibilidade total da água no solo para as plantas, envolvendo conceitos como capacidade de campo, CC, ponto de murcha permanente, PMP, porosidade de aeração, porosidade de aeração limitante, resistência a penetração, RP (Letey, 1985; Silva et al., 2009), característica imprescindível para o melhor entendimento do comportamento da água no solo, principalmente sob diferentes sistemas de manejo. A partir da CRA pode-se, também, desenvolver fórmulas matemáticas para se obter a condutividade hidráulica do solo (Mualem, 1976; van Genuchten, 1980) assim como avaliar a distribuição do tamanho dos poros do solo (Libardi, 2018).

Portanto, a determinação da CRA por si só garante a obtenção de informações relevantes quanto a organização estrutural do solo, além de possibilitar a determinação da distribuição do tamanho dos poros do solo. Espera-se assim que os resultados obtidos com as CRA's, em associação a outras importantes propriedades físicas aferidas para os diversos tratamentos deste estudo, e mais especificamente, o tratamento sob PD com rotação de culturas e diferentes plantas de cobertura, apresentem diferenças significativas em relação a condição estrutural do solo, implicando diretamente nos processos de infiltração, retenção, armazenagem e disponibilidade da água (Çerçioğlu et al., 2019). 


\section{REVISÃO BIBLIOGRÁFICA}

\subsection{Contextualização e importância dos solos}

Recursos naturais como o solo e a água são abundantes, porém, são recursos finitos no planeta terra. Eles podem ser facilmente degradados, poluídos, ou completamente destruídos quando não utilizados de maneira sustentável em qualquer atividade, seja ela de cunho agrícola, industrial ou urbana. Estima-se que em todo o território mundial ocorram fenômenos como a erosão e a degradação dos solos devido à pressão cada vez maior sobre o uso da terra para a produção de alimentos, fibras e combustíveis que decorrem, principalmente, do crescimento populacional e da expansão da malha urbana (Bridges e Oldeman, 1999). Daí, a crescente preocupação com a qualidade dos solos utilizados na agricultura, visto que o uso do solo para fins agrícolas pode alterar algumas de suas propriedades, principalmente se comparados a solos em estado natural, ou seja, aqueles que não sofreram modificações por alguma atividade antrópica.

Solos possuem importância no contexto ambiental, econômico e social pois desempenham funções vitais indispensáveis à manutenção da vida na terra. Estas funções são divididas em ecológicas e não ecológicas, sendo as ecológicas: produção vegetal de fibras, alimentos e combustíveis; preservação e manutenção das espécies humana, animal e vegetal; reservatório genético, pois abrigam inúmeros microrganismos, muitos ainda desconhecidos e com potencial para uso farmacêutico, alimentício e ambiental. Para as funções não ecológicas, tem-se: suporte físico ao desenvolvimento do espaço urbano e outras atividades antrópicas; fonte de matéria-prima vegetal e mineral à indústria; patrimônio da humanidade, onde se encontram preservados recursos históricos e culturais (Blum, 2005). As funções do solo foram também destacadas e vinculadas por Adhikari e Hartemink (2016) aos serviços ecossistêmicos, que buscam quantificar os inúmeros benefícios, tanto diretos quanto indiretos, que os recursos naturais prestam a favor da humanidade, reforçando a importância e o papel que os solos possuem e demonstrando a dependência que dele possuímos para a nossa existência. Estudos como o de Swinton et al. (2006) assumem importância cada vez maior para a elaboração de políticas mais coerentes acerca do uso do solo, a fim de garantir que as atividades agrícolas não sejam praticadas de forma prejudicial, atribuindo a estas atividades e ao solo o devido valor, que é, em sua maioria, negligenciado pelos governantes e pela população em geral (Hewitt et al., 2015). 


\subsection{Funções e qualidade dos solos}

Todos os solos possuem propriedades intrínsecas, como por exemplo a estrutura, a qual é determinada por um conjunto de fatores como relevo, clima, vegetação, material de origem, processos pedogenéticos, etc. Porém, para solos cultivados surge outro fator de extrema importância: o conjunto de técnicas de manejo utilizadas em função da atividade agrícola praticada. Elas influenciam diretamente a condição estrutural e funcional de um solo e podem tanto promover a preservação quanto a deterioração de seus atributos originais (Auler et al., 2014; Herrick, 2000).

As funções de um solo se manifestam somente àqueles aptos a desempenharem-nas, ou seja, somente em solos considerados "saudáveis". A "saúde" do solo, termo utilizado por agricultores, ou a qualidade do solo, mais comumente empregado por cientistas, pode ser avaliada pelos seus atributos físicos, químicos e biológicos, os quais englobam suas qualidades inerentes e dinâmicas. A composição e as propriedades naturais de um solo, como por exemplo a textura e os tipos de mineral de argila que o compõem, determinadas por fatores e processos de formação ao longo do tempo, são inerentes a este recurso natural, pois não podem ser influenciadas pelo manejo. Já em relação às propriedades dinâmicas, aquelas que se alteram conforme o uso e manejo num dado período possível de ser determinado na escala humana, tem-se, por exemplo a quantidade e a qualidade da matéria orgânica, a qual pode ter seus níveis vinculados às práticas de manejo (Franzluebbers, 2002; Moebius-Clune et al., 2016).

Por definição, qualidade do solo é a capacidade contínua que o solo possui para se manter funcional em conjunto com o meio ambiente e o uso da terra, sustentando a produtividade, mantendo qualidade ambiental e promovendo o bem-estar animal e vegetal (Doran e Parkin, 1994). Porém, como a qualidade do solo não pode ser diretamente aferida, cientistas do solo utilizam-se de indicadores de qualidade. Estes indicadores são traduzidos como propriedades relacionadas à parte física, química ou biológica do solo, que são sensíveis às modificações do ambiente e capazes de representarem o solo em seu estado atual, para que decisões para o manejo possam ser tomadas otimizando seu uso. Portanto, ao determinar as relações entre as propriedades dinâmicas, estes indicadores podem ser divididos em qualitativos e quantitativos, como por exemplo, a drenagem (rápida, ou lenta) e a taxa de infiltração (cm/horas), respectivamente (Doran e Parkin, 1996). No entanto, os indicadores químicos são os que têm recebido maior atenção em análises recorrentes de solos, fornecendo apenas indícios acerca de parte dos processos que ocorrem no solo, como a interação entre a solução (água pura em conjunto com diversos íons) e os sítios de troca presentes em partículas de argila e na matéria 
orgânica. A fim de exemplificar o uso destas medidas, cita-se como exemplo os valores de $\mathrm{pH}$, capacidade de troca catiônica (CTC), condutividade elétrica, entre outras. Porém, como demonstrado por Carter (1990), para uma análise efetiva acerca da qualidade dos solos é necessário que se observe diversas características por meio da determinação e correlação de diversos tipos de indicadores, avaliando-se diferentes aspectos do solo, como sua estrutura, e não somente os indicadores químicos.

Os aspectos físicos de um solo possuem relação direta com seus aspectos químicos e biológicos, influenciando os níveis e, consequentemente, os valores que se obtêm de índices de outra natureza. Portanto, na determinação da qualidade do solo, deve-se sempre avaliar os indicadores físicos e, de maneira integrada, buscar estabelecer suas inter-relações com outros índices para uma análise completa que forneça maiores indícios a respeito das propriedades do solo (Dexter, 2004; Vezzani e Mielniczuk, 2009).

\subsection{Técnicas de manejo do solo agrícola}

A técnica do plantio direto (PD), cujos primeiros registros de aplicação surgiram em meados de 1950 (Triplett e Dick, 2008; Strudley et al., 2008) consiste no não revolvimento da camada superficial do solo durante o processo de semeadura. Entretanto, não teve seu uso amplamente disseminado até aproximadamente a década de 1980, quando produtores na Austrália, América do Sul, Canada e nos Estados Unidos começaram a expandir o emprego dela diante das vantagens apresentadas, se comparada à técnica do plantio convencional (PC). O PC, diferentemente, conta com operações mecanizadas em toda a área de semeadura, no intuito de propiciar melhores condições de germinação, emergência e enraizamento ao permitir maior aeração do solo pelo revolvimento em superfície, porém apresenta quebra de estruturas importantes como os macroagregados, ou da continuidade da rede de poros formada pela matriz sólida do solo (Hammel, 1989; Lal et al., 2007).

O constante aumento da adoção do PD por produtores no mundo todo se deu em razão da obtenção de maiores níveis de produtividade para diferentes combinações de rotação de culturas em algumas lavouras e pela economia de insumos e horas de trabalho, visto que neste sistema se utiliza menor número de operações mecanizadas, promovendo a proteção da superfície do solo (Triplett e Dick, 2008). Ainda, a utilização do PD pode auxiliar no processo de conservação do solo e da água, provendo alguns serviços ecossistêmicos como aumento do sequestro de carbono e conservação da biodiversidade, porém, é mais efetivo se utilizado em conjunto à rotação de culturas e adicionalmente a algum tipo de cobertura, conhecida como 
palhada, que é a manutenção dos restos culturais, os quais devem corresponder a um valor mínimo de aproximadamente $30 \%$ deste material deixado na superfície do solo (Skaalsveen et al., 2019).

Técnicas em associação ao PD, como a manutenção dos resíduos culturais ou a utilização de plantas de cobertura, promovem benefícios à estrutura do solo, visto que a utilização de plantas de cobertura têm por objetivo evitar as perdas por processos erosivos (Derpsch et al., 1986) ao impedir que o solo fique exposto às intempéries, além de reduzir a densidade do solo (@) e promover aumento da macroporosidade (Blanco-Canqui et al., 2011; Villamil et al., 2006). Em reforço a estes resultados, o estudo de Auler et al. (2014) demonstrou que o Azévem (Lolium multiflorum L.) quando utilizado como planta de cobertura aumentou a porosidade do solo, com aumento da microporosidade, decréscimo da $\varrho$ e aumento da macroporosidade, características desejáveis para o sucesso do enraizamento e crescimento das lavouras comerciais.

Outro método benéfico à manutenção e melhoria da qualidade do solo, e que possui registros de utilização que datam de mais de um século (Lal et al., 2007), é a rotação de culturas, a qual quando utilizada em associação ao PD, apresenta resultados ainda mais expressivos (Karlen et al., 1994). Diferentemente do monocultivo, após a colheita de uma safra haverá novo plantio implementando outras espécies na mesma área, evitando assim os problemas e danos causados pelo uso sucessivo de uma mesma cultura, como demonstrado por diversos autores (Crusciol et al., 2005; Nunes et al., 2018). A prática da monocultura não é recomendada pois resulta em diminuição da variedade de espécies de microrganismos da microbiota do solo e consequente desequilíbrio desta, causando maior propensão a doenças, pragas e perda de produtividade das plantações, além de maior gasto com herbicidas, aumentando o risco ambiental e os gastos com a produção (Watts et al., 1996; Triplett e Dick, 2008).

Diante dos fatos apresentados acima, estudos mostram que a escolha das plantas para cobertura e rotação de culturas é um fator relevante, influenciando, portanto, o nível de sucesso na implementação destas técnicas. As principais diferenças observadas podem ser atribuídas à família a qual estas plantas pertencem, bem como aspectos relacionados à sua anatomia e fisiologia como por exemplo o sistema radicular, influenciando assim o tamanho dos poros do solo. Plantas da família Fabaceae, vulgarmente conhecidas como leguminosas, possuem raízes do tipo pivotante, ou seja, raízes bem desenvolvidas, mais espessas e esparsas e de menor número, e alcançam camadas mais profundas. Já as plantas da família Poacea, vulgarmente denominadas gramíneas, possuem raízes do tipo fasciculada, ou seja, raízes numerosas, porém de calibre reduzido e que alcançam maior desenvolvimento nas camadas mais superficiais do solo. As 
leguminosas possuem uma maior taxa de decomposição se comparadas às gramíneas, em razão da sua relação C:N ser baixa, o que favorece a propagação de bactérias nitrificantes benéficas ao solo e aumenta a quantidade de nitrogênio $(\mathrm{N})$ disponível as plantas, diminuindo a quantidade necessária a ser aplicada na próxima cultura. Um exemplo clássico de rotação de cultura na qual se observa esse fenômeno seria o cultivo de uma lavoura de soja (Glycine max) seguida por milho (Zea mays) (Edwards et al., 1988; Teixeira et al., 2014; Matus et al., 1997).

No entanto, estudos demonstram que a utilização do PD e suas implicações devem ser atentamente observadas, avaliando-se os aspectos físicos do solo, como a capacidade de retenção e de condução da água no solo, pois este sistema não apresentou resultados homogêneos ou totalmente benéficos para estes fenômenos em diferentes solos de diversas regiões do mundo como Brasil (Moraes et al., 2016), França (Carof et al., 2007), Italia (Castellini et al., 2013) e Nigéria (Osunbitan et al., 2005). Além disso, os solos agrícolas sofrem alteração de suas propriedades físicas originais principalmente devido as operações de cultivo realizadas, pois estas alteram a estrutura do solo, modificando todo o arranjo das partículas e do espaço poroso, o que inclui a conectividade e tamanho dos poros, afetando, consequentemente, propriedades físicohídricas como densidade do solo, lei da infiltração, condutividade hidráulica do solo, curva de retenção, interferindo diretamente na disponibilidade da água no solo para as plantas (Bouma et al., 1973).

\subsection{Propriedades físicas do solo}

O solo é composto de uma matriz sólida e um espaço poroso. A matriz consiste de sólidos minerais e orgânicos e no espaço poroso encontram-se a água em conjunto com outros elementos dissolvidos, constituindo a solução no solo, e uma solução gasosa denominada ar no solo (Hillel, 2003; Libardi, 2018). A interação desses três elementos é extremamente complexa e os processos que ocorrem no solo não são completamente entendidos, daí a importância do desenvolvimento de estudos na área da física do solo a fim de elucidar os processos transformativos que ocorrem no sistema solo-planta-atmosfera.

Constituintes como a matéria orgânica e a composição mineralógica influenciam diretamente o comportamento físico do solo, porém a matéria orgânica representa uma fração que não possui índices de fácil determinação, tornando-se difícil a caracterização por meio de processos físicos (Tisdall e Oades, 1982; Rabot et al., 2018). Já em relação aos constituintes minerais do solo, sua caracterização é dada pela análise do tamanho e arranjo das partículas sólidas ou minerais primários: a caracterização das partículas por tamanho é conhecida como 
textura e a classificação segundo o arranjo delas, refere-se à estrutura do solo (Brady e Weil, 2008).

$\mathrm{Na}$ classificação textural, as partículas são consideradas esféricas, sendo classificadas partir de dois sistemas, o do Departamento da Agricultura dos Estados Unidos (USDA) e o da Sociedade Internacional de Ciência do Solo (ISSS). Ambos buscam enquadrar os solos em classes esquematizadas em um diagrama, adotado pela sociedade Brasileira de Ciência do Solo (SBCS), conhecido como triângulo textural, cujas arestas representam as porcentagens de areia, silte e argila (Ferreira, 2010). A textura é a característica intrínseca mais estável quando comparada às mudanças sofridas pelo manejo e por isso é utilizada com a finalidade de classificação dos solos. Além da textura, existe ainda outro atributo intrínseco, a densidade de partículas, que auxilia na caracterização física, a qual representa a relação da massa dos sólidos pelo volume dos sólidos, como, por exemplo, os minerais de argila cujos valores variam de 2200 a $2600 \mathrm{~kg} \mathrm{~m}^{-3}$ e o quartzo, de 2500 a $2800 \mathrm{~kg} \mathrm{~m}^{-3}$ (Libardi, 2018).

A estrutura é a característica física que diz respeito à agregação das partículas e, como as unidades minerais estão ligadas e interconectadas, geralmente elas se ligam por meio de elementos cimentantes como óxidos, minerais de argila e carbonatos que se encontram presentes em sua estrutura, cujas quantidades variam conforme a composição química e biológica de cada perfil. Este arranjo é influenciado diretamente pelas forças atuantes que o mantém, tornando a estrutura do solo um atributo muito variável pela ação do ambiente e condições em que este se encontra (Tormena et al., 1999). Pela estrutura, determinam-se propriedades relativas à arquitetura do solo, como tamanho e estabilidade de agregados, e outras propriedades como densidade do solo, quantidades armazenadas do elemento carbono, além da curva de retenção da água, por meio da qual podem ser avaliadas outras propriedades físico-hídricas (Rabot et al., 2018). Medidas acerca da estrutura possuem caráter qualitativo, ou seja, não existem meios práticos para obtenção destes dados, sendo necessário realizar análises laboratoriais para a determinação e respectiva caracterização dos agregados e do espaço poroso, que representam os principais constituintes estruturais do solo. Por meio de estudos mais aprofundados sobre os agregados, é possível obter informações como seu formato (laminar, granular, prismático e angular), tamanho (diâmetro), e grau de desenvolvimento (estabilidade). Adicionalmente, buscamse determinar aspectos relativos aos vazios ou espaço poroso existentes do solo, que constituem o principal meio de caminhamento e transporte dos líquidos e gases, também denominado sistema poroso do solo (SPS). Neste SPS, verifica-se a existência de poros com diferentes tamanhos e, devido a isso, possuem diferentes funções. Maiores informações e detalhes acerca da conectividade de poros, tortuosidade e definição do tamanho do raio dos poros são obtidas pelo 
emprego de técnicas mais elaboradas de análises por imagem 2D, como o método dos blocos impregnados por resina ou em 3D, por meio da microtomografia (Pires et al., 2017; Medeiros et al., 2014), e também da tomografia computadorizada de raio X (Crestana e Vaz, 1998; Wildenschild et al., 2002). Estas técnicas visam auxiliar na compreensão sobre a arquitetura dos espaços existentes entre estes agregados ou dentro deles, permitindo com isso estudar microscopicamente os fenômenos físicos e as interações que podem ocorrer entre as três diferentes fases constituintes do sistema sólidos-solução-ar e chegar a conclusões sobre velocidade de caminhamento de substâncias no solo.

Os processos de formação e estabilização dos agregados ocoreem em diferentes níveis hierárquicos, isto é, de acordo com a escala que se divide em macroagregados $(3,0 \mathrm{~mm})$, microagregados $(0,3 \mathrm{~mm})$, submicroagregados $(0,03 \mathrm{~mm})$ e partículas primárias $(0,003 \mathrm{~mm})$ (Oades e Waters, 1991). Em relação ao manejo, é um trabalho dinâmico pois leva em consideração a soma das cargas energéticas impostas pelo ambiente ao solo, havendo tendência de formação de agregados maiores para os solos bem manejados, que são os agregados mais desejáveis, no entanto os agregados menores estão presentes em maior quantidade e principalmente quando o solo sofreu compactação ou desagregação pelos diversos processos erosivos (Herrick et al., 2001; Wander et al., 1994).

Por intermédio de medidas da densidade do solo (@), também é possível acessar o estado de qualidade do solo pois é uma característica relativa a estrutura e fornece informação acerca do manejo adotado. Mesmo havendo tendência de solos arenosos possuírem valores maiores de $\varrho$ do que solos argilosos, é pelo cálculo da densidade que se chega à conclusão da existência de compactação, ou seja, quando ocorre diminuição do espaço poroso do solo devido ao uso excessivo de maquinas ou pisoteio animal pela pecuária, o que resulta em danos severos ao desenvolvimento radicular das plantas cultivadas, alterando sua produtividade e na pior das hipóteses evitando sua emergência (Logsdon e Karlen, 2004). Ainda, a partir da relação entre valores de densidade do solo e densidade de partículas calcula-se a porosidade do solo $(\beta)$.

A fração argila refere-se às partículas do solo com diâmetro efetivo $<2 \mu \mathrm{m}$ e pode ser considerada como a fração mais importante do solo, visto que são nas partículas desta fração que estão presentes os sítios de troca de íons atuantes, isto é, onde estão as cargas e os elementos químicos adsorvidos que controlam e participam das reações e processos físico-químicos do solo. Os minerais de argila presentes na fração argila e conhecidos como argila coloidal, podem quando em solução flocular ou dispersar de forma que ao flocularem estão passando por combinação de suas partículas formando agregados ou quando dispersadas encontrar-se-ão em suspensão, 
alterando prejudicialmente a estrutura e a estabilidade dos agregados. Portanto, solos que possuem minerais de argila com maior capacidade de floculação são solos mais estáveis, possuindo menores índices de erosão. Diante destas afirmações, trabalhos como o de Kay e Dexter (1990) demonstram a importância de determinar-se a quantidade de argila dispersa, quando esta se encontra em solução aquosa, e isto é obtido por meio de medidas indiretas da quantidade extraída de acordo com área específica dos agregados exposta a ação do fluído, pois mudanças nas práticas de manejo influenciarão a formação e as condições dos processos de agregação do solo bem como do tamanho destes agregados, principalmente daqueles encontrados nas camadas mais superficiais do solo (Fuller et al., 1995).

A condutividade hidráulica do solo K é uma propriedade hídrica essencial para o estudo do movimento da água no solo e pode ser determinada em amostras no laboratório ou no campo, em condições de solo saturado e não-saturado (Hillel 2003; Libardi et al., 1980). Sendo uma propriedade que quantifica a intensidade do movimento da água, é dependente do espaço poroso e varia com a distribuição do tamanho dos poros no solo. A condutividade hidráulica é, portanto, mais dependente da estrutura do que da textura do solo e quanto maior for o grau de agregação de um solo, maior será o valor a ela atribuído (Gonçalves e Libardi, 2013). Outro aspecto importante que deve ser considerado é a distribuição do tamanho de poros do solo, visto que a compactação ocorre quando o solo, submetido a forças externas, é comprimido diminuindo a quantidade de macroporos com alteração do processo de infiltração de água (Carof et al., 2007; Tormena et al., 1998), e da resistência do solo à penetração. Conforme Alaoui et al. (2011), deve-se incluir a análise da alteração da estrutura porosa do solo nos modelos hidromecânicos pois tal alteração influencia diretamente as propriedades hídricas do solo manifestando-se na alteração do fluxo de água, principalmente em macroporos (jarvis). Para uma avaliação detalhada da distribuição dos poros, em muitos estudos são utilizadas técnicas sofisticadas como o raio-x e tomografia computadorizada, nas quais é possível obter-se uma visão da geometria dos poros no volume de solo estudado.

\subsection{Curva de retenção da água no solo, CRA}

As partes constituintes do solo, isto é, seu sistema poroso e sua parte sólida conhecida como matriz, são responsáveis pelo fenômeno da retenção da água e a explicação de como a água é retida fundamenta-se nos fenômenos da capilaridade e adsorção. A capilaridade atua principalmente nos microporos do solo, estando associadas às interfaces curvas ar-àgua (força capilar); já o processo de adsorção está associado às interfaces sólido-solução (força de adsorção), 
e o somatório dessas duas forças tem sido denominado força mátrica (Hillel 2003; Libardi, 2018). Ainda, em relação às propriedades do solo, a geometria irregular dos poros e as variações em textura e mineralogia são as razões primárias que influem na capacidade do solo em reter a água, muito embora outras propriedades podem ser utilizadas para descrever e fornecer maiores indícios acerca deste fenômeno como as propriedades hídricas, morfológicas, químicas e do tamanho de partículas, em que se tem, por exemplo, a quantidade de carbono orgânico, densidade do solo, constituição da fração argila e taxa de adsorção do sódio (Rawls et al., 2003).

O potencial matricial ou mátrico $\left(\phi_{\mathrm{m}}\right)$ da água no solo varia com o conteúdo de água $(\theta)$ no solo, esta dependência, $\phi_{\mathrm{m}}(\theta)$, ou também $\theta\left(\phi_{\mathrm{m}}\right)$, é normalmente expresso na forma de um gráfico denominado curva de retenção da água no solo (CRA), cuja determinação é quase sempre feito em laboratório por meio de funis de Haines e câmaras de pressão de Richards (Klute, 1986; Libardi, 2018).

Os níveis de energia com que a água se encontra retida na matriz do solo são influenciados por diversos fatores, sendo também alterados pelo tipo de cultivo utilizado, principalmente nas amostras das camadas mais superficiais do perfil do solo. Esta alteração nos níveis de energia de retenção da água pode modificar significativamente o volume de água da chuva que infiltra desde estas camadas até as mais profundas, incluindo, principalmente, a zona radicular, onde se concentra o maior volume de água disponível às plantas. O plantio e o cultivo do solo aumentam, de forma geral, a porosidade, modificando a distribuição do tamanho dos poros e ocasionando mudanças no formato das CRA's e na condutividade hidráulica. Alteração do nível de energia também pode ocorrer em função da densidade do solo (Ahuja et al., 1998).

A quantidade e o tipo de argila também influenciam a retenção da água. Por exemplo, solos com teor de argila maior que 10\% apresentam sempre maior retenção de água e com muito maior efeito se a argila for 2:1 (montmorillonita) em comparação a argila 1:1 (caulinita). Adicionalmente, a capacidade de troca catiônica (CTC) do solo também possui influência sobre o fenômeno de retenção, pois esta é decorrente do tipo de minerais de argila que constituem o solo (Kutílek et al., 2006; Rawls et al., 2003).

A necessidade de se ter uma função contínua para estimar a CRA gerou modelos matemáticos de ajuste de $\theta$ em função de $\phi_{\mathrm{m}}$, os mais utilizados sendo os que empregam funções exponenciais, como os propostos por Brooks e Coorey (1964), Campbell (1974) e van Genutchen (1980). A principal diferença entre o modelo utilizado por van Genutchen (VG) e o de Brooks \& Coorey (BC), é que o primeiro permite a total representação da CRA, já o de BC não. No trabalho de van Genutchen (1980), foi desenvolvido modelo para obtenção de fórmula 
matemática, a partir da equação de ajuste da CRA, da condutividade hidráulica relativa em função do conteúdo de água, $\mathrm{K}_{\mathrm{r}}(\theta)$, que é a razão da função $\mathrm{K}(\theta)$ pela condutividade hidráulica do solo saturado, $\mathrm{K}_{0}$.

Este trabalho teve como objetivo determinar a CRA e estimar a partir dela a distribuição do tamanho de poros e a disponibilidade de água para as plantas, bem como determinar a condutividade hidráulica do solo saturado e prever, por modelo matemático a partir da CRA, a condutividade hidráulica relativa, $\mathrm{K}_{\mathrm{r}}$. 


\section{MATERIAL E MÉTODOS}

\subsection{Localização e caracterização da área experimental}

A área do experimento situa-se no Centro Experimental Central do Instituto Agronômico de Campinas (IAC) na Fazenda Santa Elisa, em Campinas, SP, Brasil, 22 54' S, 47 05' W, 669 m de altitude (Figura 1). O clima da região é tropical de altitude do tipo Cwa, segundo classificação Köppen, e possui temperatura média de $24^{\circ} \mathrm{C}$ com verões quentes e úmidos, pluviosidade média de 229,5 mm em janeiro e invernos de temperaturas amenas e pluviosidade média de $28,2 \mathrm{~mm}$ em julho. A pluviosidade média anual é de $1.398 \mathrm{~mm}$, porém mal distribuída ao longo do ano.

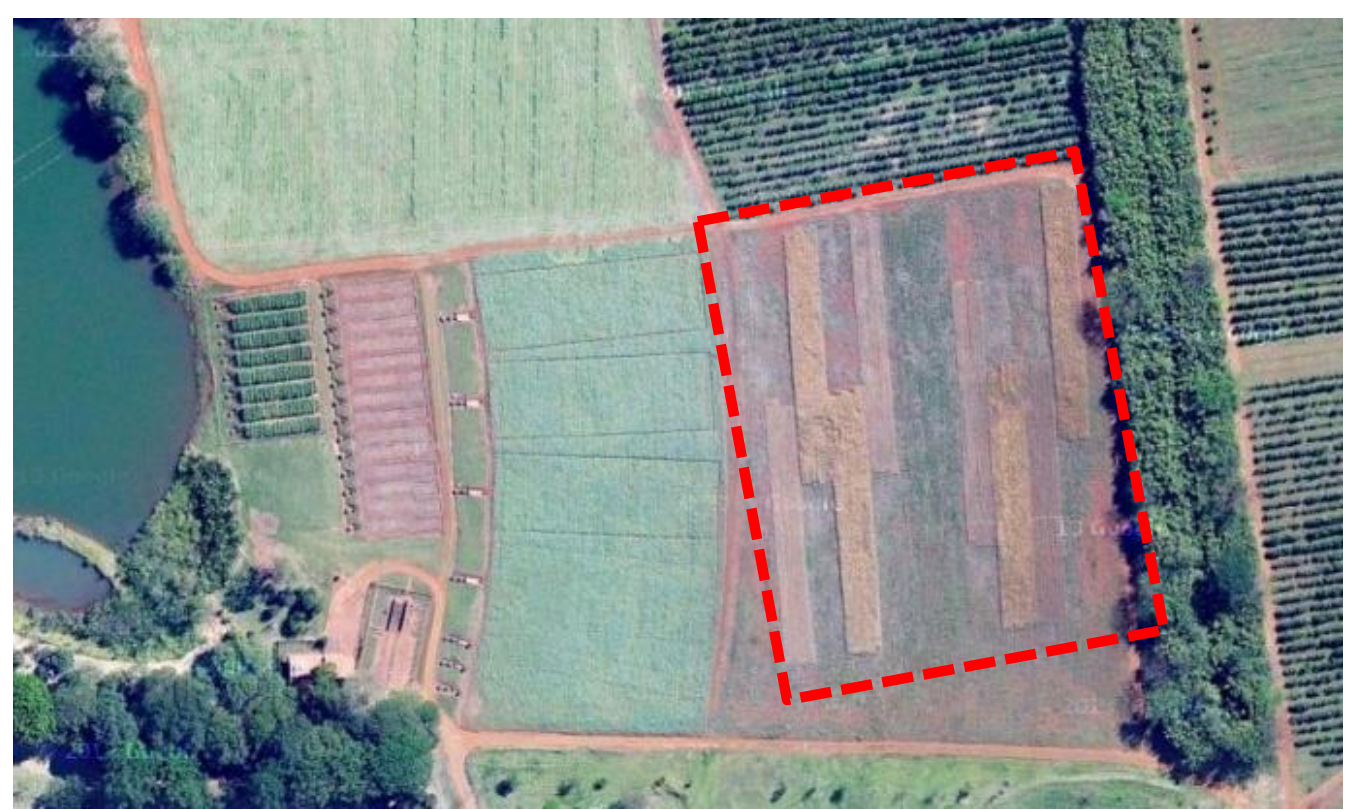

Figura 1. Estação Experimental Central do Instituto Agronômico de Campinas (Fazenda Santa Elisa).

O solo da área experimental foi classificado como Latossolo Vermelho Eutrófico férrico, argiloso a muito argiloso, bem drenado e com declividade de aproximadamente $2 \%$ (Santos et al., 2018).

\subsection{Histórico da área experimental}

$\mathrm{Na}$ área de 2,2 ha foi instalado um experimento no ano agrícola de 2005/2006, utilizando-se o sistema de plantio direto. Para isso, foi feita uma aração e duas gradagens e, para uma melhor uniformização da área, foi realizada uma calagem com calcário dolomítico na camada 
de 0,00-0,20 m. Nas diferentes parcelas foram utilizadas primeiramente plantas de cobertura na entressafra, para posterior plantio de culturas sobre a palhada e, para as áreas de pousio, não ocorreu nenhum cultivo (Tabela 1);

Tabela 1. Histórico de plantio da área experimental.

\begin{tabular}{|c|c|c|c|}
\hline Ano & Safra/Entressafra (gramínea) & Entressafra (leguminosa) & Pousio \\
\hline 2005 & Aveia & Chicharo & Pousio \\
\hline $2005 / 2006$ & Soja & & \\
\hline 2006 & Milheto & Mucuna & Pousio \\
\hline $2006 / 2007$ & Soja & & \\
\hline 2007 & Triticale & Chicharo & Pousio \\
\hline $2007 / 2008$ & Soja & & \\
\hline 2008 & Aveia & & Pousio \\
\hline $2008 / 2009$ & Milho & & \\
\hline 2009 & Triticale & Crotalária & Pousio \\
\hline $2009 / 2010$ & Soja & & \\
\hline 2010 & Triticale & Crotalária & Pousio \\
\hline $2010 / 2011$ & Soja & & \\
\hline 2011 & Triticale & Crotalária & Pousio \\
\hline $2011 / 2012$ & Soja & & \\
\hline 2012 & Aveia & Crotalária & Pousio \\
\hline $2012 / 2013$ & Soja & & \\
\hline 2013 & Milheto & & \\
\hline $2013 / 2014$ & Soja (perdido) & & \\
\hline 2014 & Triticale (perdido) & & \\
\hline $2014 / 2015$ & Milho & & \\
\hline 2015 & Triticale & & \\
\hline $2015 / 2016$ & Milho & & \\
\hline 2016 & Braquiária ruziziensis & & \\
\hline $2016 / 2017$ & Sorgo forrageiro & & \\
\hline $2017 / 2018$ & Milheto (fogo) & & \\
\hline 2018 & Milheto & Crotalaria (perdido) & Pousio \\
\hline 2018 & Sorgo & Feijao de Porco & Pousio \\
\hline
\end{tabular}

Na safra de 2016 /2017, anteriormente à implementação do experimento, ocorreu incêndio acidental, sendo o plantio de milheto considerado perdido.

Em 03/2018 deu-se início ao experimento pelo cultivo das plantas do tipo gramínea e leguminosa, porém com a escassez das chuvas não se obteve sucesso na implantação das culturas.

Após, em 08/2018 ocorreu a quebra do ciclo de algumas áreas de PD com operações de aragem utilizando-se grade aradora com 16 discos (24 polegadas cada) e grade niveladora para quebra de torrões, ambas tracionadas por trator (Massey Fergusson 4275), obtendo ao fim da operação efetividade de $0,20 \mathrm{~m}$ de profundidade. Os restos culturais presentes anteriormente nas 
áreas de PD, agora denominadas PC-Gramínea e PC-Leguminosa foram incorporados em profundidade, sendo que nas áreas de pousio não havia a existência de palhada.

Finalmente, em 09/2018, no período chuvoso, ocorreu plantio do sorgo-forrageiro (Sorghum bicolor L.) como a espécie do tipo gramínea e do feijão-de-porco (Canavalia ensiformis L.) como a espécie do tipo leguminosa, e em 11/2018 houve dessecação das plantas de cobertura das parcelas sob PD, utilizando-se 1,50 $\mathrm{L} \mathrm{ha}^{-1}$ de ingrediente ativo glifosato e $0,50 \mathrm{~L} \mathrm{ha}^{-1}$ de paraquate com pulverizador autopropelido (Massey Ferguson MF 9030).

\subsection{Delineamento experimental e caracterização dos tratamentos}

O delineamento experimental foi feito a partir de três blocos casualizados com parcelas subdivididas, sendo o fator da parcela o manejo do solo (Plantio Direto - PD e Preparo Convencional - PC) e o fator da subparcela três tipos de cobertura do solo (milheto, crotalária e sem cobertura - pousio) em sucessão ao cultivo de inverno (aveia/trigo) e ao cultivo de verão (feijão), contabilizando 18 unidades experimentais. As parcelas experimentais possuem $800 \mathrm{~m}^{2}$ $(80,0 \times 10,0 \mathrm{~m})$ e $200,0 \mathrm{~m}^{2}(20,0 \times 10,0 \mathrm{~m})$. A Figura 2 mostra a distribuição das parcelas na área experimental.

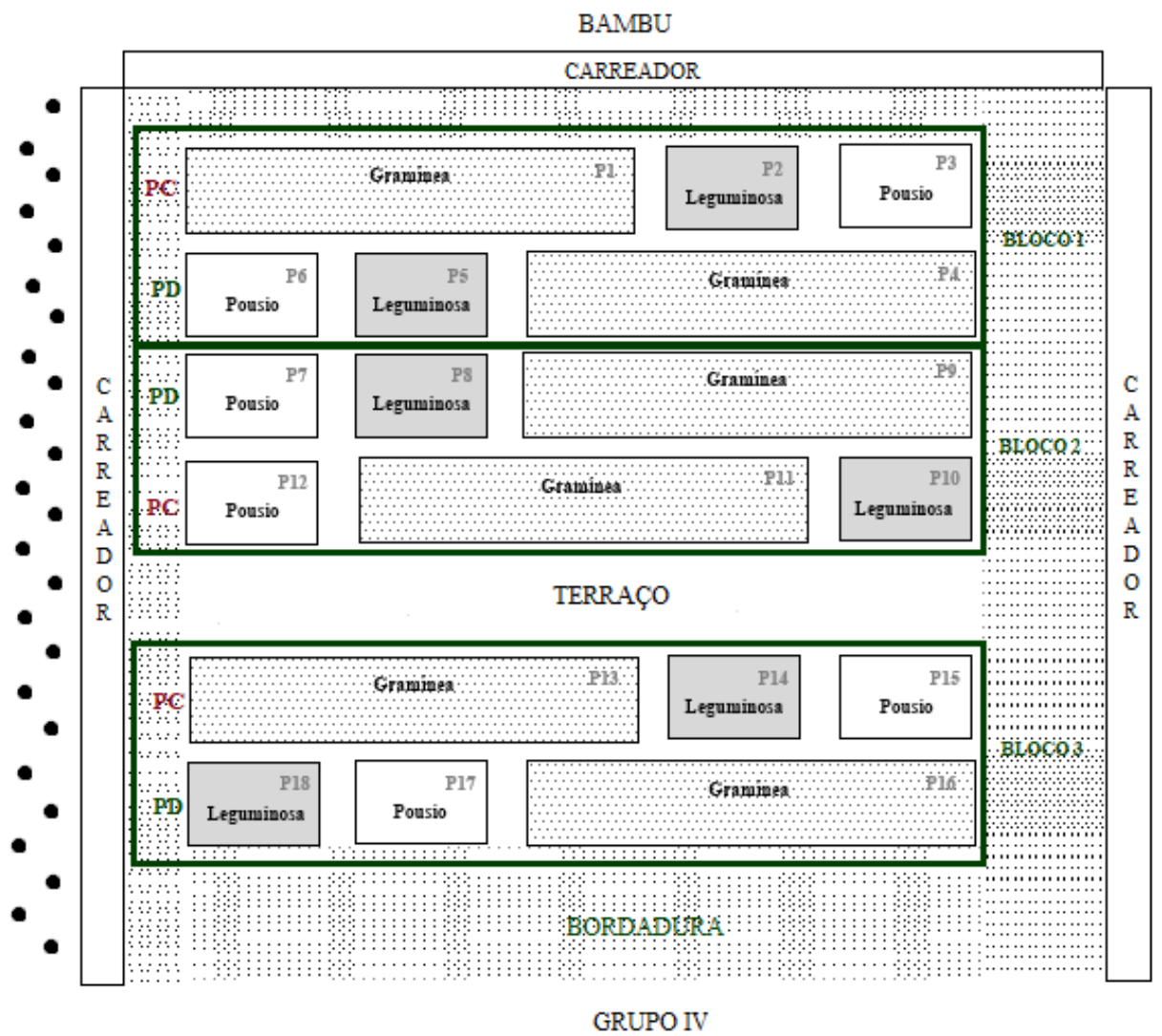

Figura 2. Croqui da área experimental. 


\subsection{Coleta do solo e preparo das amostras}

A amostragem foi realizada em 12/2018, quando foram coletadas amostras com estrutura deformada e indeformada, as quais foram utilizadas, a primeira, para determinação da granulometria, densidade de partículas, carbono orgânico, argila dispersa em água e a segunda, para obtenção da densidade do solo, curva de retenção da água no solo e outros parâmetros físico-hídricos que dela derivam, como a porosidade, a distribuição do tamanho de poros e a condutividade hidráulica relativa. As coletas foram feitas de quatro camadas diferentes: 0,00-0,05 m, 0,05-0,10 m, 0,10-0,20 m, e 0,20-0,30 m, para cada bloco com as parcelas dos diferentes sistemas de plantio e cobertura em um esquema 3 × 2 × 3 (3 coberturas x 2 sistemas de plantio, x 3 repetições), representando um total de 144 anéis de amostras indeformadas em duplicata $[(3 \times 2 \times 3) \times 4$ camadas $\times 2$ amostras por camada] e 72 amostras deformadas [(3x2x3) x 4 camadas] coletadas. Para a coleta das amostras indeformadas utilizou-se o extrator de Uhland tradicional (figura 3-A), e para as amostras deformadas utilizou-se o trado holandês (figura 3-B). Após coletadas, as amostras indeformadas foram devidamente embaladas para preservação da estrutura durante o transporte (figura 3-C) e corretamente armazenadas em ambiente com umidade e temperatura controlada (incubadora), a fim de se preservar ao máximo a estrutura que se encontra em campo. As amostras deformadas foram levadas a casa de vegetação para secagem à sombra por um período de 7 a 10 dias (figura 3-D), após foram passadas por peneira de malha $2 \mathrm{~mm}$ (figura 3-E) com auxílio de um socador (figura 3-F), obtendo-se ao fim terra fina seca ao ar (TFSA). 

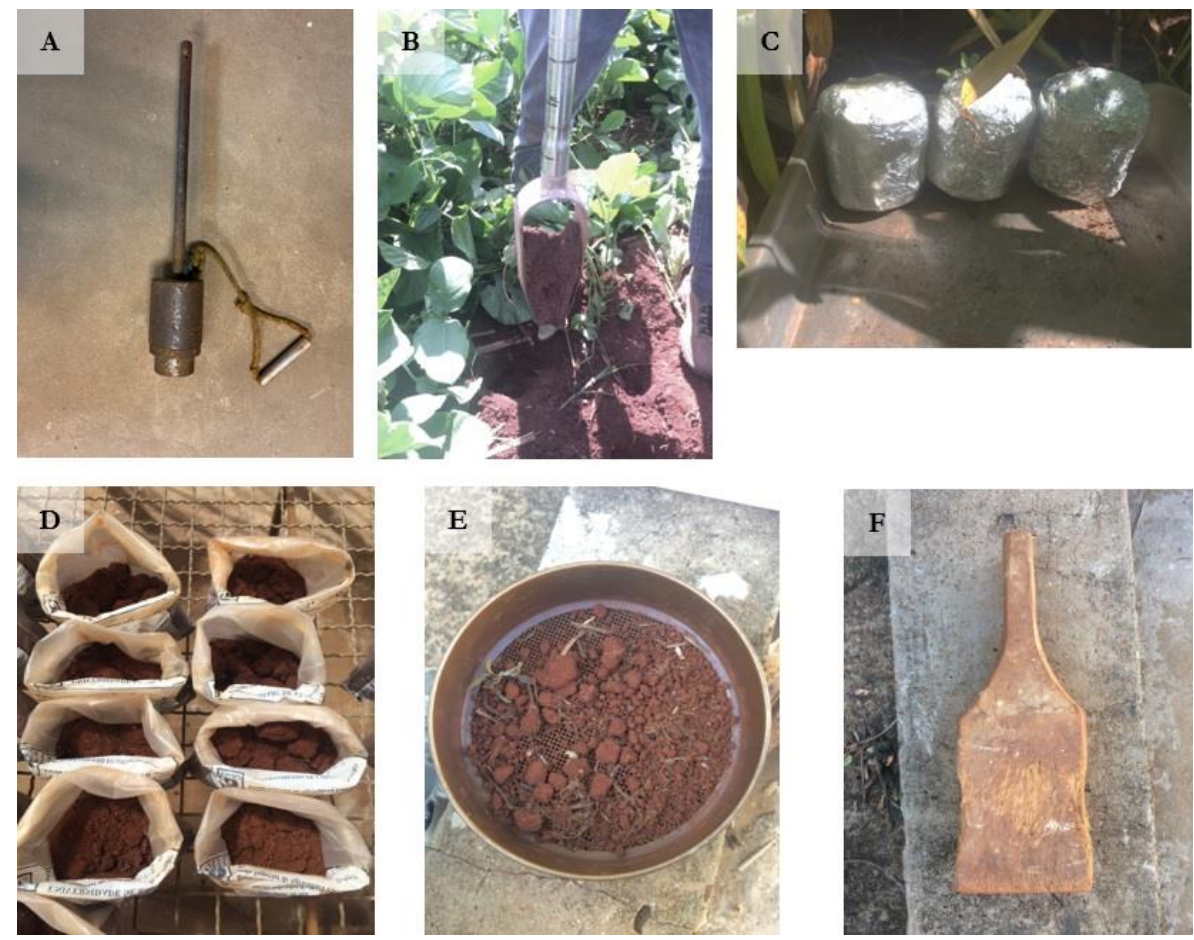

Figura 3. Coleta e preparo das amostras de solo.

\subsection{Análises realizadas}

\subsubsection{Densidade das partículas e granulometria do solo}

Para obtenção dos valores da densidade de partículas do solo utilizaram-se amostras de terra fina seca em estufa (TFSE), isto é, amostras deformadas que passaram por peneira de malha $(2 \mathrm{~mm})$, e foram levadas à estufa a $105^{\circ} \mathrm{C}$ por $24 \mathrm{~h}$. Após obtenção de TFSE, empregou-se o método do picnômetro a gás hélio utilizando o instrumento - Accupyc 1330, Micrometrics Instrument Corporation (figura 4-A), o qual utiliza uma cápsula de metal (figura 4-B) com conteúdo de aproximadamente $6 \mathrm{~g}$ (figura 4-C) de TFSE para a análise (Flint e Flint, 2002). 

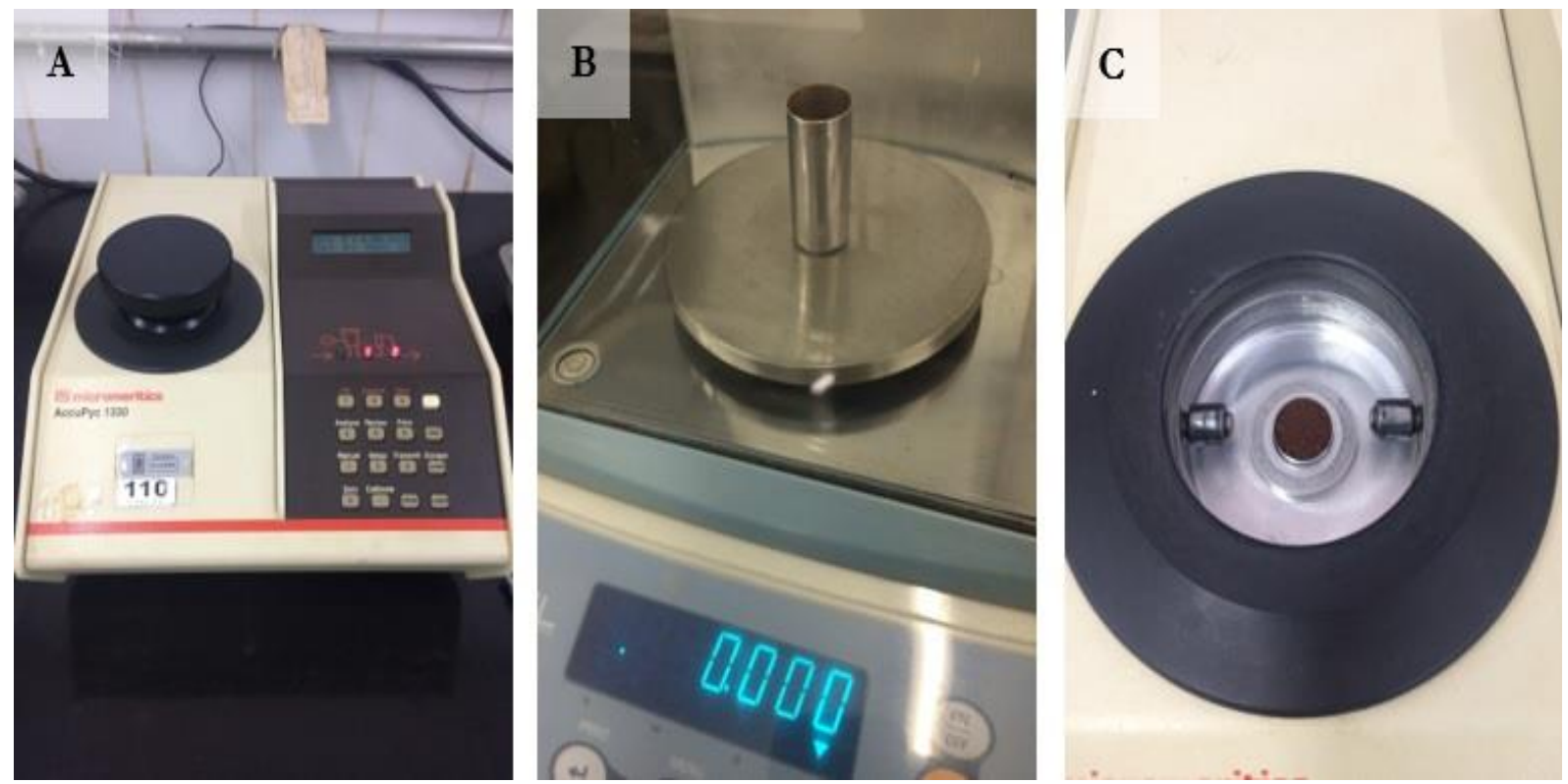

Figura 4. Análise laboratorial para densidade de partículas do solo.

Para estas análises utilizaram-se amostras compostas, obtendo-se um total de 12 amostras, respeitando as repetições por bloco e por profundidade $(3 \times 4)$, visto que textura e densidade de partículas são características inerentes ao solo e independentes do manejo e tipo de cobertura. As cifras apresentadas para a densidade das partículas, como consta na tabela 2 , são médias obtidas a partir dos dados obtidos para cada repetição por profundidade.

A fim de caracterizar granulometricamente o solo da área estudada, foi empregado o método da pipeta (USDA, 1996) para as amostras compostas e deformadas (figura 5-A, B, C).

A classificação textural obtida, de acordo com o triângulo de classes utilizado pela SBCS, foi muito argilosa, visto que o solo apresentou valores de argila correspondente a mais de 60\%, ou maiores que $600 \mathrm{~g}$ para cada quilograma de solo. Os valores para cada fração constituinte (areia, silte e argila) também se encontram na tabela 2. 

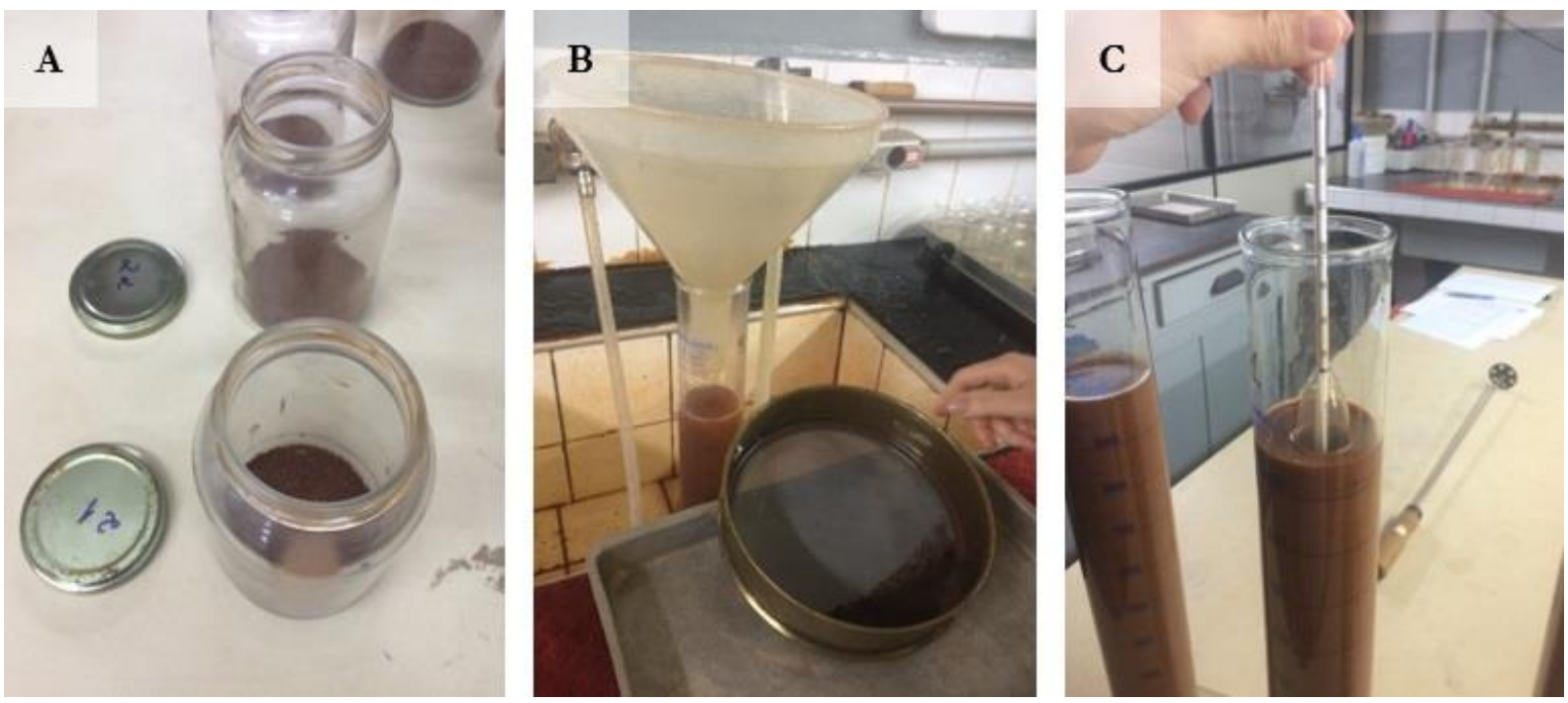

Figura 5. Processo da caracterização granulométrica.

Tabela 2. Frações granulométricas e densidade das partículas das amostras compostas para cada profundidade.

\begin{tabular}{ccccccc}
\hline Profundidade & Areia & Silte & Argila & & Classificação textural & @s \\
\cline { 2 - 4 } $\mathrm{m}$ & & $\mathrm{g} \mathrm{kg}^{-1}$ & & & & $\mathrm{~g} \mathrm{~cm}^{-3}$ \\
$0,00-0,05$ & 287 & 105 & 608 & & muito argilosa & 2,94 \\
$0,05-0,10$ & 282 & 110 & 608 & & muito argilosa & 2,93 \\
$0,10-0,20$ & 260 & 107 & 633 & & muito argilosa & 2,95 \\
$0,20-0,30$ & 261 & 89 & 650 & & muito argilosa & 2,96 \\
\hline
\end{tabular}

\subsubsection{Argila Dispersa em Água}

A partir de amostras de TFSA de cada parcela experimental, isto é, amostras deformadas do solo seco à sombra passadas em peneira de malha de $2 \mathrm{~mm}$ e para as quatro profundidades estabelecidas para este estudo, foram avaliadas: a argila prontamente dispersa em água (APDA) e a argila mecanicamente dispersa em água (AMDA).

As avaliações da APDA e da AMDA foram realizadas pela metodologia desenvolvida por Kay e Dexter (1990) utilizando o equipamento 2100AN TURBIDIMETER Hach ${ }^{\circledR}$ (figura 6-A). A análise consistiu em colocar $5 \mathrm{~g}$ de TFSA em um recipiente com capacidade de $150 \mathrm{~mL}$, completando o volume restante com água deionizada, sendo posteriormente levado à agitação, processo no qual ocorre a dispersão das partículas de argila. Da mesma porção de TFSA utilizada para as análises, foram separadas $5 \mathrm{~g}$ para determinação do conteúdo de água de cada amostra de TFSA.

Para determinar a APDA realiza-se a agitação manualmente, fazendo-se 4 inversões do recipiente com a água e a amostra. Após este procedimento, as amostras são deixadas em repouso total por período de aproximadamente 16 h (Figura 6-B). Após este período transfere-se uma 
alíquota de $30 \mathrm{~mL}$ para um outro recipiente translúcido (Figura 6-C e D) utilizado para análise no turbidímetro, obtendo-se assim as leituras na unidade NTU (unidades de turbidez nefelométrica), sendo que 1 NTU equivale a $1 \mathrm{ppm}$ de argila em solução, ou ainda, na unidade de argila em NTU g ${ }^{-1} \mathrm{~L}^{-1}$, conforme (Kay e Dexter, 1990).

Já para obtenção dos valores de AMDA, utilizam-se os mesmos procedimentos, porém, aplicando-se às amostras agitação mecânica, a fim de impor maiores cargas sobre estas, sendo o processo realizado por um agitador mecânico (Figura 6-E), cujo ciclo era de aproximadamente 120 agitações por minuto por um período de 30 min por amostra.
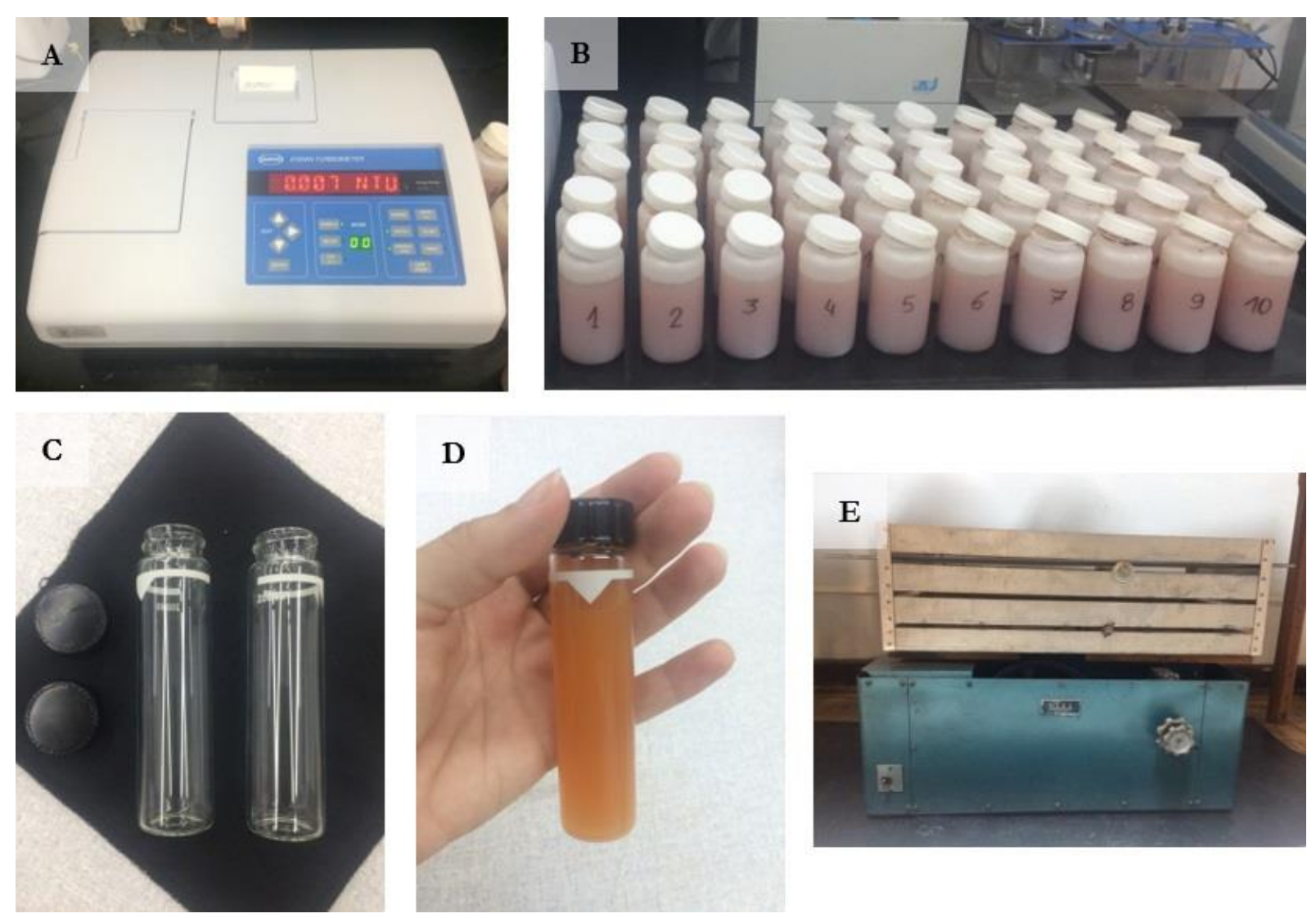

Figura 6. Processos para análise de APDA e AMDA.

Os valores obtidos através desta análise encontram-se explicitados nas tabelas 3 e 4. 
Tabela 3. Argila prontamente dispersa em água, APDA, para os dois tipos de cultivo (plantio direto e convencional), para as três coberturas (gramínea, leguminosa e pousio), nas quatro profundidades do solo $(0,00-0,05 \mathrm{~m} ; 0,05-0,10 \mathrm{~m} ; 0,10-0,20 \mathrm{~m} ; 0,20-0,30 \mathrm{~m})$.

\begin{tabular}{|c|c|c|c|}
\hline \multirow{2}{*}{ Profundidade } & \multicolumn{3}{|c|}{ Cobertura } \\
\hline & Gramínea & Leguminosa & Pousio \\
\hline \multirow[t]{2}{*}{$\mathrm{m}$} & 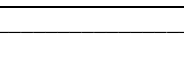 & JTU $g^{-1} L^{-1}$ & \\
\hline & \multicolumn{2}{|c|}{ Direto } & \\
\hline $0,00-0,05$ & 1,23 & 0,87 & 1,37 \\
\hline $0,05-0,10$ & 1,42 & 1,56 & 1,16 \\
\hline $0,10-0,20$ & 1,91 & 1,64 & 1,60 \\
\hline \multirow[t]{2}{*}{$0,20-0,30$} & 1,50 & 1,36 & 1,36 \\
\hline & \multicolumn{2}{|c|}{ Convencional } & \\
\hline $0,00-0,05$ & 1,25 & 1,32 & 1,21 \\
\hline $0,05-0,10$ & 1,09 & 1,32 & 1,16 \\
\hline $0,10-0,20$ & 1,34 & 1,92 & 1,21 \\
\hline $0,20-0,30$ & 1,70 & 1,93 & 1,19 \\
\hline
\end{tabular}

Tabela 4. Argila mecanicamente dispersa em água, AMDA, para os dois tipos de cultivo (plantio direto e convencional), para as três coberturas (gramínea, leguminosa e pousio), nas quatro profundidades do solo $(0,00-0,05 \mathrm{~m} ; 0,05-0,10 \mathrm{~m} ; 0,10-0,20 \mathrm{~m} ; 0,20-0,30 \mathrm{~m})$.

\begin{tabular}{cccc}
\hline \multirow{2}{*}{ Profundidade } & \multicolumn{3}{c}{ Cobertura } \\
\cline { 2 - 4 } m & \multicolumn{2}{c}{ Leguminosa } & Pousio \\
\cline { 2 - 4 } & \multicolumn{2}{c}{ Direto } & NTU g $^{-1} \mathrm{~L}^{-1}$ \\
$0,00-0,05$ & 20,31 & 18,74 & 19,50 \\
$0,05-0,10$ & 23,02 & 28,51 & 21,42 \\
$0,10-0,20$ & 29,70 & 34,74 & 36,50 \\
$0,20-0,30$ & 24,44 & 30,20 & 34,11 \\
& Convencional & & \\
$0,00-0,05$ & 23,42 & 15,58 & 16,44 \\
$0,05-0,10$ & 22,47 & 17,33 & 18,53 \\
$0,10-0,20$ & 26,18 & 23,09 & 19,03 \\
$0,20-0,30$ & 26,61 & 29,81 & 18,98 \\
\hline
\end{tabular}

\subsubsection{Carbono orgânico total, C}

O carbono orgânico das amostras de solo foi determinado pelo método da combustão a seco, utilizando o analisador elementar LECO-CN do Laboratório de Biogeoquímica Ambiental (LBA) da EMBRAPA Meio Ambiente, Jaguariúna-SP. Os valores obtidos estão explicitados na tabela 5 abaixo. 
Tabela 5. Carbono orgânico total, C, para os dois tipos de cultivo (plantio direto e convencional), para as três coberturas (gramínea, leguminosa e pousio), nas quatro profundidades do solo $(0,00-0,05 \mathrm{~m} ; 0,05-0,10 \mathrm{~m} ; 0,10-0,20 \mathrm{~m} ; 0,20-0,30 \mathrm{~m})$.

\begin{tabular}{|c|c|c|c|}
\hline \multirow{2}{*}{ Profundidade } & \multicolumn{3}{|c|}{ Cobertura } \\
\hline & Gramínea & Leguminosa & Pousio \\
\hline \multirow[t]{2}{*}{$\mathrm{m}$} & & $\mathrm{g} \mathrm{Kg}^{-1}$ & \\
\hline & \multicolumn{2}{|c|}{ Direto } & \\
\hline $0,00-0,05$ & 22,3 & 21,0 & 21,6 \\
\hline $0,05-0,10$ & 20,8 & 18,0 & 17,2 \\
\hline $0,10-0,20$ & 19,3 & 17,0 & 16,0 \\
\hline \multirow[t]{2}{*}{$0,20-0,30$} & 17,0 & 15,0 & 12,1 \\
\hline & \multicolumn{2}{|c|}{ Convencional } & \\
\hline $0,00-0,05$ & 18,8 & 20,3 & 19,9 \\
\hline $0,05-0,10$ & 18,4 & 18,3 & 18,2 \\
\hline $0,10-0,20$ & 18,0 & 16,6 & 18,0 \\
\hline $0,20-0,30$ & 14,5 & 13,0 & 12,6 \\
\hline
\end{tabular}

\subsubsection{Densidade do solo, $\rho$}

A densidade do solo (@) foi determinada a partir das amostras indeformadas, as quais foram coletadas em duplicata, tendo sido utilizadas primeiramente para obtenção das CRA's, e após para determinação da $\varrho$.

O método utilizado foi o do anel volumétrico (Grossman e Reinsch, 2002) e o cálculo feito pela razão entre a massa do solo seco em estufa, $m_{s}$, e o volume do anel de amostragem, V (equação 1). Primeiramente foi realizada pesagem da amostra com o anel, levando a seguir, o conjunto à estufa com $105^{\circ} \mathrm{C}$ por $48 \mathrm{~h}$, realizando nova pesagem e então o cálculo da massa de solo seco. Para o volume dos anéis utilizou-se paquímetro digital, efetuando duas medidas de altura e duas de diâmetro para cada anel, utilizando para os cálculos de volume a média destas medidas.

$$
\rho=\frac{m_{s}}{V} \rightarrow\left[k g m^{-3}\right]
$$

Os valores obtidos para a densidade do solo encontram-se explicitados na tabela 6. 
Tabela 6. Densidade do solo, @, para os dois tipos de cultivo (plantio direto e convencional), para as três coberturas (gramínea, leguminosa e pousio), nas quatro profundidades do solo (0,00-0,05m; 0,05-0,10m; 0,10-0,20m; 0,20-0,30m).

\begin{tabular}{|c|c|c|c|}
\hline \multirow{2}{*}{ Profundidade } & \multicolumn{3}{|c|}{ Cobertura } \\
\hline & Gramínea & Leguminosa & Pousio \\
\hline \multirow[t]{2}{*}{$\mathrm{m}$} & & kg. $\mathrm{dm}^{-3}$ & \\
\hline & \multicolumn{2}{|c|}{ Direto } & \\
\hline $0,00-0,05$ & 1,26 & 1,21 & 1,35 \\
\hline $0,05-0,10$ & 1,32 & 1,31 & 1,28 \\
\hline $0,10-0,20$ & 1,32 & 1,24 & 1,38 \\
\hline \multirow[t]{2}{*}{$0,20-0,30$} & 1,33 & 1,29 & 1,30 \\
\hline & \multicolumn{2}{|c|}{ Convencional } & \\
\hline $0,00-0,05$ & 1,30 & 1,19 & 1,22 \\
\hline $0,05-0,10$ & 1,29 & 1,15 & 1,25 \\
\hline $0,10-0,20$ & 1,32 & 1,35 & 1,29 \\
\hline $0,20-0,30$ & 1,35 & 1,29 & 1,26 \\
\hline
\end{tabular}

\subsubsection{Resistência à penetração}

A resistência do solo à penetração foi obtida a partir das amostras indeformadas avaliadas conforme Bradford (1986) (figura 7) com a utilização de um penetrômetro de bancada (CT3 Texture Analyzer, Brookfield ${ }^{\circledR}$ ) que possui em sua constituição uma célula de carga de $25 \mathrm{~kg}$ com haste de ponta penetrante em formato cônico de ângulo aproximadamente $30^{\circ}$ e diâmetro de $3,81 \mathrm{~mm}$. A velocidade atingida pela haste foi de $10 \mathrm{~mm} \mathrm{~min}^{-1}$ e o conteúdo de água no solo $(\theta)$ foi o equivalente à tensão aplicada de $15 \mathrm{kPa}$, que corresponde ao ponto de murcha permanente (PMP). Os dados obtidos foram processados pelo software embutido ao equipamento, sendo dado em unidades de kgf e posteriormente transformados para unidades de MPa. Estes valores podem ser vistos na tabela 7 . 


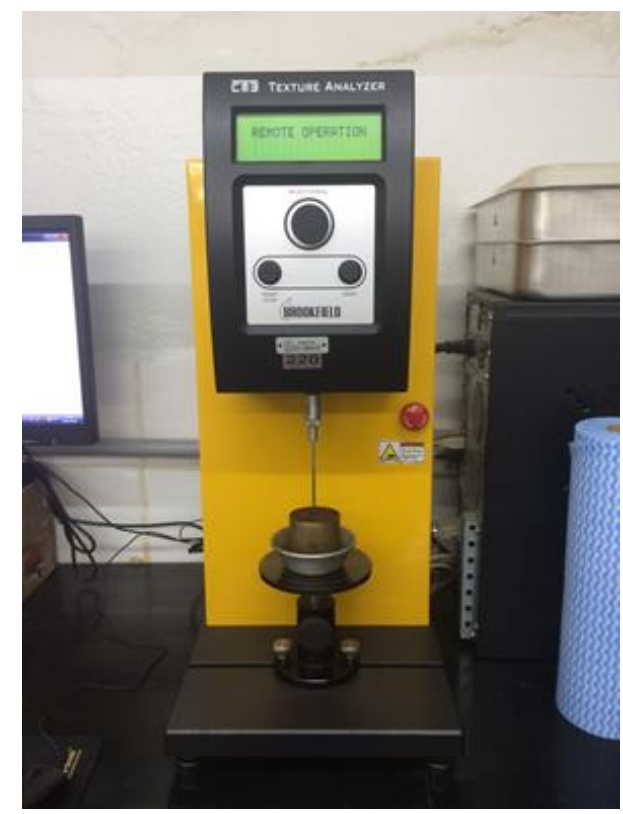

Figura 7. Penetrômetro de bancada.

Tabela 7. Valores de resistência a penetração, RP, para os dois tipos de cultivo (plantio direto e convencional), para as três coberturas (gramínea, leguminosa e pousio), nas quatro profundidades do solo $(0,00-0,05 \mathrm{~m} ; 0,05-0,10 \mathrm{~m} ; 0,10-0,20 \mathrm{~m} ; 0,20-0,30 \mathrm{~m})$.

\begin{tabular}{|c|c|c|c|c|c|c|}
\hline \multirow{2}{*}{ Profundidade } & \multicolumn{3}{|c|}{ Cobertura } & \multicolumn{3}{|c|}{ Conteúdo de água - $\theta$} \\
\hline & Gramínea & Leguminosa & Pousio & Gramínea & Leguminosa & Pousio \\
\hline \multirow[t]{2}{*}{$\mathrm{m}$} & & $\mathrm{MPa}$ & $\bar{C}$ & & $-\mathrm{m}^{3} \mathrm{~m}^{-3}$ & \\
\hline & \multicolumn{3}{|c|}{ Direto } & & & \\
\hline $0,00-0,05$ & 1,90 & 2,29 & 4,51 & 0,28 & 0,23 & 0,30 \\
\hline $0,05-0,10$ & 3,32 & 3,12 & 1,95 & 0,26 & 0,25 & 0,29 \\
\hline $0,10-0,20$ & 3,74 & 3,35 & 4,94 & 0,28 & 0,23 & 0,28 \\
\hline $0,20-0,30$ & 3,68 & 3,40 & 3,95 & 0,26 & 0,26 & 0,30 \\
\hline \multicolumn{7}{|c|}{ Convencional } \\
\hline $0,00-0,05$ & 4,46 & 2,16 & 2,98 & 0,25 & 0,28 & 0,23 \\
\hline $0,05-0,10$ & 4,24 & 1,55 & 2,84 & 0,28 & 0,23 & 0,26 \\
\hline $0,10-0,20$ & 2,08 & 4,39 & 3,05 & 0,26 & 0,24 & 0,21 \\
\hline $0,20-0,30$ & 5,50 & 2,49 & 3,99 & 0,25 & 0,27 & 0,25 \\
\hline
\end{tabular}

Os dados obtidos para RP foram ajustados com auxílio da ferramenta estatística $\mathrm{R}^{\circledR}$ pelo ajuste de Busscher (1990), o qual estima parâmetros empíricos.

\subsubsection{Curva de Retenção da Água no solo}

As CRA's foram obtidas por secagem, sendo primeiramente realizado a "toalete" das amostras indeformadas, retirando o solo excedente com lâmina cortante (figura 8-A). Após, com o intuito de evitar a perda de material, fixou-se um pano de peso desprezível com elástico de 
borracha para a fixação na base inferior do anel (figura 8-B), garantindo que as amostras mantivessem sempre o mesmo volume calculado do anel, cujo valor foi posteriormente utilizado para realização de diversos cálculos, para obtenção das curvas de retenção. As CRA's foram determinadas com auxílio de dois aparatos laboratoriais, os funis de placa porosa ou funis de Haines (figura 8-C), para tensões aplicadas de 1, 3, 6 e $10 \mathrm{kPa}$, e as câmaras de pressão de Richards com placas porosas (figura 8-D) para pressões aplicadas de 50, 100, 500 e $1500 \mathrm{kPa}$, seguindo os procedimentos descritos em Libardi (2018).

O princípio de funcionamento do funil difere da câmara: enquanto que no funil se aplica uma sucção de h metros de água à amostra (equação 2) na câmara aplica-se uma pressão de ar $\mathrm{P}$ (equação 3) para retirada da água obtendo-se, respectivamente, uma tensão $\tau=\mathrm{h}$ $($ energia $/$ peso $=\mathrm{m})$ com o funil e uma tensão $\tau=\mathrm{P}($ energia $/$ volume $=\mathrm{Pa})$ com a câmara. Em outras palavras, com ambos os equipamentos se fixa um determinado potencial mátrico $\phi_{\mathrm{m}}$ que nada mais é do que a tensão com o sinal trocado $\left(\phi_{\mathrm{m}}=-\tau\right)$ e quanto maior $\phi_{\mathrm{m}}$ (menor $\tau$ ), menor o conteúdo de água na amostra.

$$
\tau=h=\frac{2 \sigma}{\rho_{a} g r} \rightarrow\left[m \equiv m_{H_{2} O}\right]
$$

em que $\sigma=$ tensão superficial, $\varrho_{\mathrm{a}}=$ densidade da solução (água), $\mathrm{g}=$ aceleração da gravidade.

$$
\tau=P=\frac{2 \sigma}{r} \rightarrow[\text { energia } / \text { volume }]
$$

As amostras foram reutilizadas a cada nova tensão, sendo o processo de saturação realizado sempre por períodos de $18 \mathrm{~h}-24 \mathrm{~h}$ utilizando-se água deionizada e de-aerada (figura 8-D). A saturação consistiu em elevar o nível de água acima da metade da altura do anel quando dentro dos funis (figura 8-E) para as respectivas sucções aplicadas ou dentro de uma bandeja (figura 8-F), para posterior colocação nas câmaras de pressão de Richards. Estes procedimentos foram repetidos à cada novo valor de tensão, completando assim nove processos de secagemmolhagem ao longo do tempo de obtenção das curvas, visto que foram avaliadas um total de nove tensões. Após aplicação de cada sucção (ou pressão) esperou-se o período suficiente para que se atingisse o equilíbrio hidrostático nas amostras, ou seja, para que o conteúdo de água $(\theta)$ na amostra, correspondente à tensão aplicada, não mais variasse o que era verificado pela ausência de gotejamento. Em seguida, obteve-se o valor da massa de solo úmido $\left(\mathrm{m}_{\mathrm{u}}\right)$ de cada amostra pela pesagem das amostras em balança analítica devidamente aferida. Após obtenção de 
todos os valores para $\mathrm{m}_{\mathrm{u}}$, levaram-se as amostras à secagem em estufa por período de $48 \mathrm{~h}$ à $105{ }^{\circ} \mathrm{C}$ para obtenção de valores da massa de solo seco $\left(\mathrm{m}_{\mathrm{s}}\right)$ do solo. Ao se relacionar os valores de $\mathrm{m}_{\mathrm{u}}$ e $\mathrm{m}_{\mathrm{s}}$, é possível calcular o conteúdo de água a base de massa (U) para cada amostra em cada tensão avaliada (equação 4) e, pela equação (5) obter o conteúdo de água á base de volume $(\theta)$, em que $\varrho$ é a densidade do solo e $\varrho_{a}$ a densidade da água, aqui considerada $=1000 \mathrm{~kg} \mathrm{~m}^{-3}$. Estes cálculos foram efetuados para todas as amostras e as respectivas tensões a elas aplicadas.

$$
\begin{gathered}
U=\frac{m_{u}-m_{s}}{m_{s}} \rightarrow\left[k g k g^{-1}\right] \\
\theta=\frac{\rho}{\rho_{a}} U \rightarrow\left[m^{3} m^{-3}\right]
\end{gathered}
$$

Para o ajuste dos dados observados das CRA's utilizou-se como ferramenta o software TableCurve $2 \mathrm{D}^{\circledR}$ e a equação de ajuste foi a utilizada por van Genutchen (1980) (equação 6) para ser aplicada no modelo matemático Mualem-Van Genutchen de previsão da condutividade hidráulica relativa do solo.

$$
\theta=\theta_{r}+\frac{\theta_{s}-\theta_{r}}{\left[1+\left(\alpha|\phi m|^{n}\right)\right]^{m}} \rightarrow\left[m^{3} m^{-3}\right]
$$

em que $\theta_{\mathrm{s}}$ é o conteúdo de água no solo saturado, $\theta_{\mathrm{r}}$ é o conteúdo de água residual (correspondente a $\tau=1500 \mathrm{kPa}$ ), e $\alpha, \mathrm{m}, \mathrm{n}$, são parâmetros empíricos, sendo $\mathrm{m}=1-1 / \mathrm{n}$. 

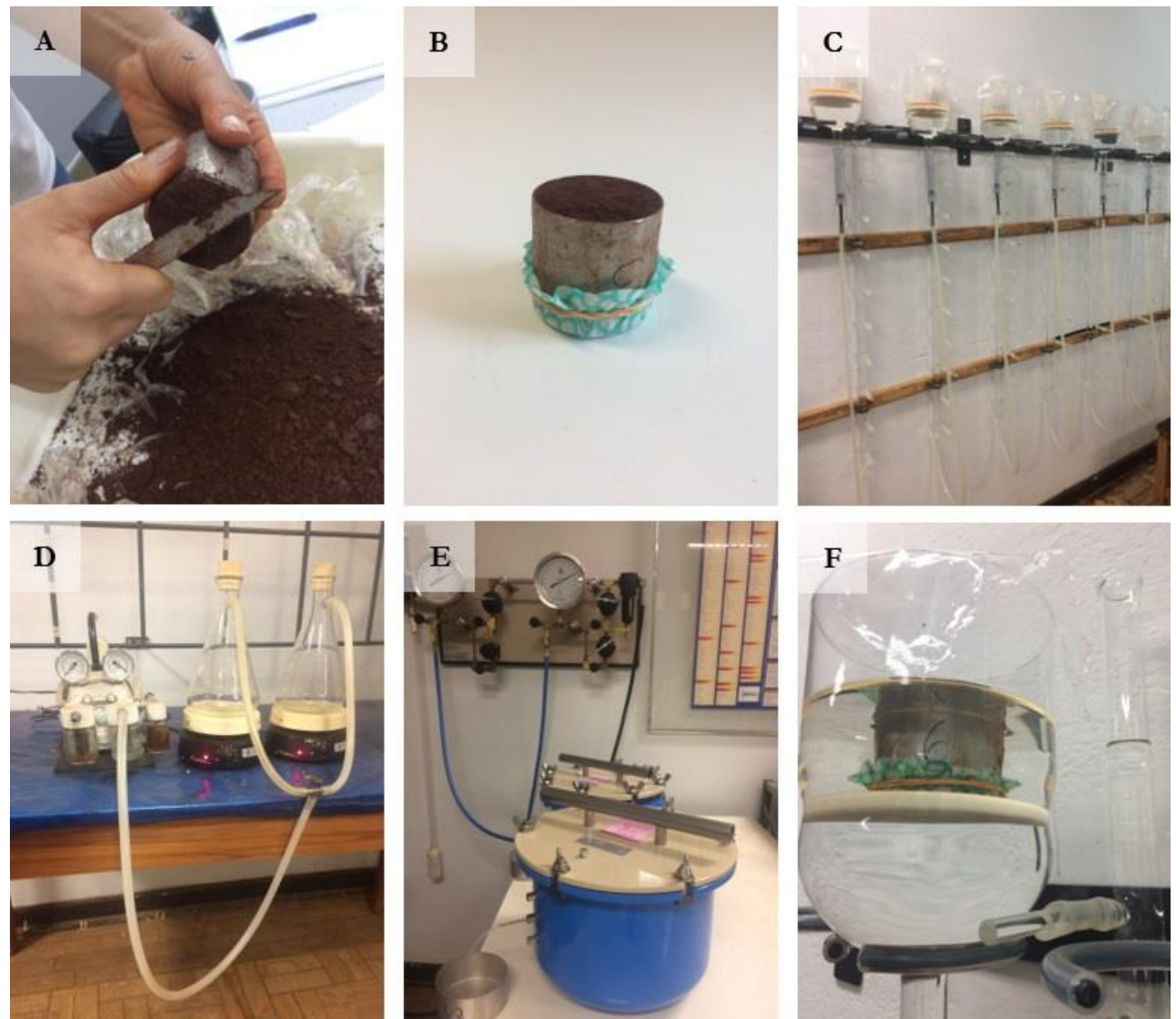

Figura 8. Processo de obtenção das CRA’s em laboratório.

\subsection{Propriedades físicas estimadas a partir da CRA ajustada}

\subsubsection{Porosidade do solo}

A porosidade do solo $\alpha$ é a fração do volume de poros do volume total de uma amostra de solo. É determinada experimentalmente conforme sua definição, mas pode ser calculada a partir das densidades das partículas e do solo pela equação (7). Porém, ao se realizar o ajuste dos dados da CRA pela equação (6), pode-se considerar o $\theta_{\mathrm{s}}$ como um parâmetro da equação e assumir o $\theta_{\mathrm{s}}$ resultante do ajuste como a porosidade $\alpha$. Portanto, ao obter-se o parâmetro conteúdo de água de saturação $\left(\theta_{\mathrm{s}}\right)$ pelo ajuste de Mualem-van Genutchen, pode-se inferir o valor de $\alpha \mathrm{em} \mathrm{m}^{3} \mathrm{~m}^{-3}$.

$$
\alpha=\left(1-\frac{\rho}{\rho_{s}}\right) 100 \rightarrow[\%]
$$

\subsubsection{Curva de distribuição do tamanho dos poros}

A partir das CRA's é possível, pela aplicação de equações matemáticas, obter-se a curva da função frequência de raios de poro, a qual descreve que uma amostra de solo a uma tensão $(\tau)$ ao 
atingir o equilíbrio terá esvaziado poros com um raio equivalente maior do que o raio correspondente àquela tensão, sendo este raio calculado pela equação (8) da teoria da capilaridade. É possível perceber que o aumento da tensão utilizada acarreta o esvaziamento de poros cada vez menores, sendo possível dizer que os raios a serem primeiramente esvaziados são os macroporos, subsequentemente os mesoporos e depois microporos, lembrando que nunca haverá o total esvaziamento destes microporos, quando a água na faixa de alta pressão pode se encontrar retida por adsorção às partículas do solo e não mais pelo fenômeno da capilaridade. Ao conteúdo de água nesta faixa de alta pressão $(1500 \mathrm{kPa})$ tem sido atribuído o nome de conteúdo de água residual $\left(\theta_{\mathrm{r}}\right)$, o qual é obtido pelo ajuste das CRA's pela equação utilizada por van Genutchen (1980). A classificação dos poros pelo raio equivalente em macro, meso e microporos neste trabalho obedece a proposta por Koorevaar et al. (1983), a qual define para $\tau=10 \mathrm{kPa}$ o raio equivalente igual à $15 \mu \mathrm{m}$, sendo os poros menores que este raio denominado microporos, e para $\tau=3 \mathrm{kPa}$ o raio equivalente será de $50 \mu \mathrm{m}$, em que os poros maiores que $50 \mu \mathrm{m}$ são os chamados macroporos e, finalmente, para tensões entre 3 e $10 \mathrm{kPa}$, ou para os raios maiores do que $15 \mu \mathrm{m}$ e menores que $50 \mu \mathrm{m}$ têm-se os mesoporos.

$$
r_{s}=\frac{2 \sigma}{\tau} \rightarrow[m]
$$

Transformando o eixo das abcissas da CRA de $\log \tau$ para $\log r_{s}$ e o eixo das ordenadas de $\theta$ para saturação relativa $(\omega)$, que corresponde a fração cheia de água do volume de poros da amostra de solo, isto é, chamando de $\beta$ a porosidade do solo (equação 9).

$$
\omega=\frac{\theta}{\beta} \equiv \frac{\theta}{\theta_{s}} \rightarrow[\text { admensional }]
$$

Obtém-se a curva da função frequência acumulada de raios, $\omega=\mathrm{F}\left(\log r_{s}\right)$, cuja equação de ajuste considerando a equação (6) para o ajuste da CRA, é dada pela equação (10). Diferenciando a equação (10) em relação a $\log r_{s}$ obtém-se a inclinação da tangente à curva da função $\mathrm{F}\left(\log r_{S}\right)$ para todos os pontos $\left(\log \mathrm{r}_{\mathrm{s}}, \mathrm{S}_{\mathrm{r}}\right)$ resultando na equação (11), que é a equação da função frequência de raios $f\left(\log r_{s}\right)$.

$$
\omega=F\left(\log r_{s}\right)=\omega_{r}+\frac{1-\omega_{r}}{\left[1+\left(\frac{2 \sigma \alpha}{\rho g r_{s}}\right)^{n}\right]^{m}} \rightarrow[\text { admensional }]
$$


em que $\omega_{\mathrm{r}}=\theta_{\mathrm{r}} / \theta_{\mathrm{s}}, \sigma=$ tensão superficial da água, $\varrho_{\mathrm{a}}=$ densidade da água e $\mathrm{g}=$ acelaração da gravidade.

$$
\frac{d \omega}{d \log r_{s}}=f\left(\log r_{s}\right)=\left(1-\omega_{r}\right) m n\left(\frac{2 \sigma \alpha}{\rho g r_{s}}\right)^{n}\left[1+\left(\frac{2 \sigma \alpha}{\rho g r_{s}}\right)^{n}\right]^{-(m+1)} \rightarrow[\text { admensional }]
$$

A derivada da equação (11), igualada a zero fornece, matematicamente, o raio equivalente $r_{s}$ correspondente à frequência de máxima, ou $r_{\mathrm{s} \text { max }}$, no caso resultando na equação (12)

$$
r_{\text {smax }}=\frac{2 \sigma \alpha}{\rho g} m^{\frac{1}{n}} \rightarrow[m]
$$

\subsubsection{Condutividade hidráulica relativa, $\mathrm{K}_{\mathrm{r}}$}

A saturação relativa efetiva é dada pela equação (13) abaixo:

$$
\omega_{e}=\frac{\theta-\theta r}{\theta s-\theta r} \rightarrow[\text { admensional }]
$$

A equação de van Genutchen (1980) para a função $\mathrm{K}_{\mathrm{r}}\left(\omega_{\mathrm{e}}\right)$ obtida a partir da CRA e ajustada para equação (6), com base no modelo de Mualem (1976) e que foi aqui utilizada é:

$$
k_{r}\left(\omega_{e}\right)=\omega_{e}^{\frac{1}{2}}\left[1-\left(1-\omega_{e}^{\frac{1}{m}}\right)^{m}\right]^{2} \rightarrow[\text { adimensional }]
$$

para $\mathrm{m}=1-1 / \mathrm{n}$.

\subsubsection{Intervalo de água disponível, IAD}

A capacidade de água disponível é definida como a diferença entra a capacidade de campo, CC, e o ponto de murcha permanente, PMP. A CC é o valor máximo de conteúdo de água retida pelo solo após a drenagem excessiva (esvaziamento dos macroporos), e o PMP é o valor máximo de conteúdo de água no solo necessário para a planta não morrer ou murchar permanentemente. Em outras palavras, a CC é o limite máximo de disponibilidade de água no solo para as plantas e o PMP o limite mínimo (Veihmeyer e Hendrickson, 1949; Silva et al., 1994).

Historicamente muitas tentativas foram feitas para determinar estes dois índices da CAD no laboratório. Nos dias de hoje ainda se utiliza a CRA para avalia-las: considera-se o CC como o conteúdo de água no solo correspondente ao potencial mátrico de $-33 \mathrm{kPa}$ (para solos argilosos) e 
-10 kPa (para solo arenoso) e o PMP como o conteúdo de água correspondente ao potencial mátrico de $-1500 \mathrm{kPa}$

\subsection{Estatística}

Os dados obtidos foram tratados estatisticamente com auxílio do software SISVAR ${ }^{\circledR}$, realizando assim os testes de variância $(F=p \leq 0,05)$ e de média (Tuckey $=5 \%$ de significância). 


\section{RESULTADOS}

As variáveis nas quais as diferenças entre as suas médias foram significativas pela estatística foram AMDA, APDA, carbono total, RP, porosidade de aeração, e conteúdo volumétrico de água disponível $\theta_{\text {DIsp. }}$ Para densidade do solo (@) não se obteve nenhum grau de influência dos fatores avaliados neste estudo (manejo, cobertura, profundidade, e suas interações).

\subsection{Argila dispersa}

\subsubsection{Argila Prontamente Dispersa em Água}

A partir dos dados obtidos e utilizando a ferramenta estatística SISVAR, apresenta-se a figura 9, a qual nos diz que para APDA houve somente influência do fator profundidade, ou seja, o fator manejo e o fator cobertura não estão influenciando os valores de APDA, a qual foi significativamente maior $(\mathrm{p} \leq 0,05)$ para a camada $0,10-0,20 \mathrm{~m}$ de profundidade.

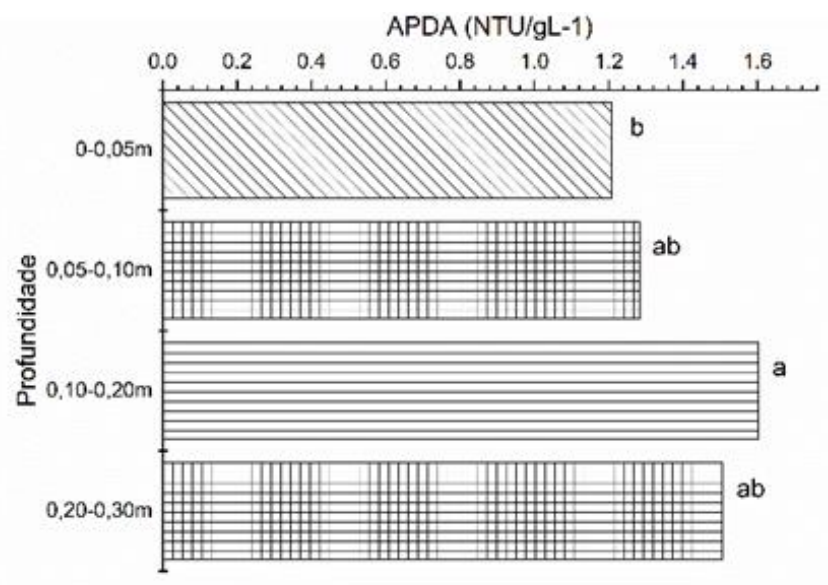

Figura 9. Teor médio de Argila Prontamente Dispersa em Água, APDA, para as profundidades avaliadas. Letras comparam e demonstram as diferenças dos valores apresentados para o fator significante, determinado pelo teste Tukey a $5 \%$.

\subsubsection{Argila Mecanicamente Dispersa em Água}

Os fatores que influenciaram os níveis de AMDA, pelos resultados obtidos, são manejo (figura 10) e profundidade (figura 11), para os quais PD apresentou diferença significativa ( $\mathrm{p} \leq 0,05)$. As camadas mais profundas $0,10-0,20 \mathrm{~m}$ e $0,20-0,30 \mathrm{~m}$ de profundidade foram as que se diferenciaram das demais apresentando contendo os maiores valores (figura 11). 


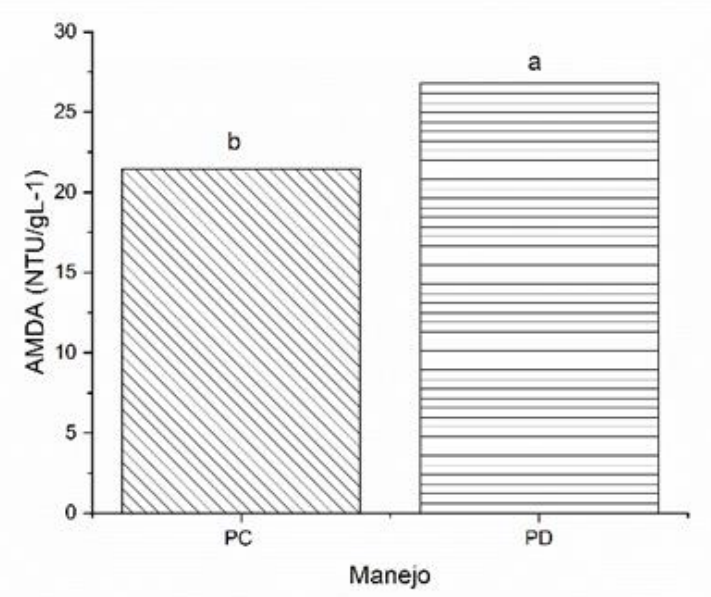

Figura 10. Teores médias de Argila Mecanicamente Dispersa em Água, AMDA, para os manejos avaliados (PC e PD). Letras comparam e demonstram as diferenças dos valores apresentados para o fator significante, determinado pelo teste Tukey a $5 \%$.

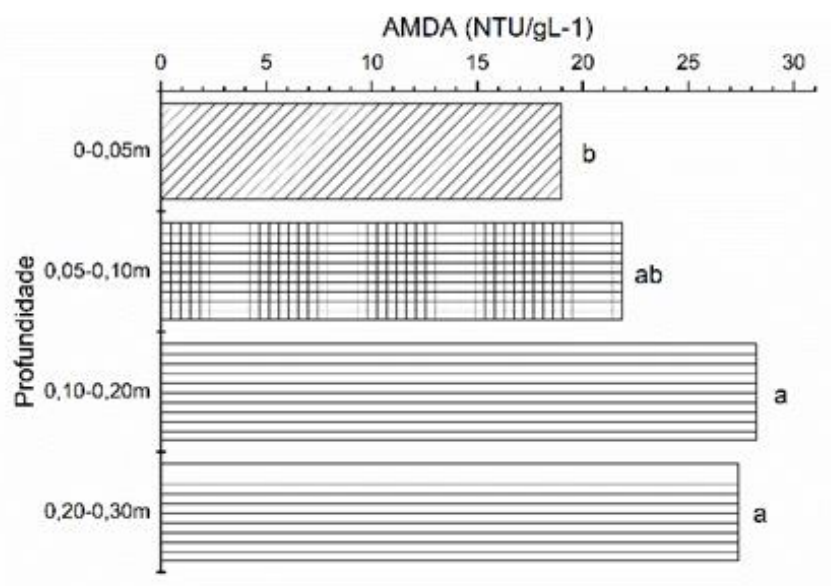

Figura 11. Teor médio de Argila Mecanicamente Dispersa em Água, AMDA, para as profundidades avaliadas $(0,00-0,05 \mathrm{~m} ; 0,05-0,10 \mathrm{~m} ; 0,10-0,20 \mathrm{~m}$; e 0,20-0,30 m). Letras comparam e demonstram as diferenças dos valores apresentados para o fator significante, determinado pelo teste Tukey a 5\%.

\subsection{Carbono Total, C}

Os resultados obtidos para a quantificação de $\mathrm{C}$ mostram que os fatores que influenciam os seus níveis são manejo e cobertura, havendo interação significativa entre os dois fatores (figura 12), sendo que a cobertura gramínea no sistema PD foi a que se diferenciou positivamente das demais coberturas $(\mathrm{p} \leq 0,05)$. 


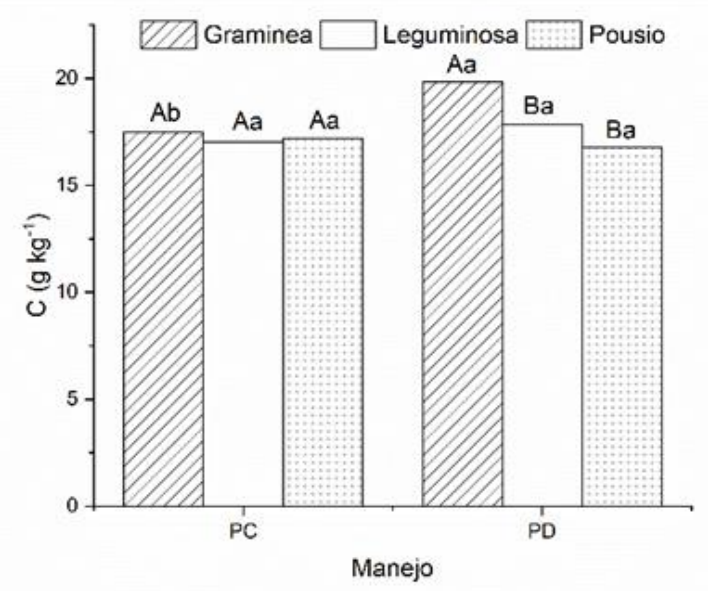

Figura 12. Teor médio de carbono, C, para as coberturas avaliadas (gramínea, leguminosa e pousio) em ambos os manejos (PD e PC). Letras minúsculas comparam os manejos dentro de cada cobertura e letras maiúsculas comparam as coberturas dentro de cada manejo pelo teste de Tukey ao nível de 5\% de significância.

\subsection{Resistência à penetração, RP}

Os valores apresentados para RP mostram que os fatores que a influenciam são manejo e cobertura, havendo interação significativa entre os dois fatores (figura 13), e que o pousio em PD foi o que se diferenciou apresentando o maior valor em comparação às demais coberturas $(\mathrm{p} \leq 0,05)$.

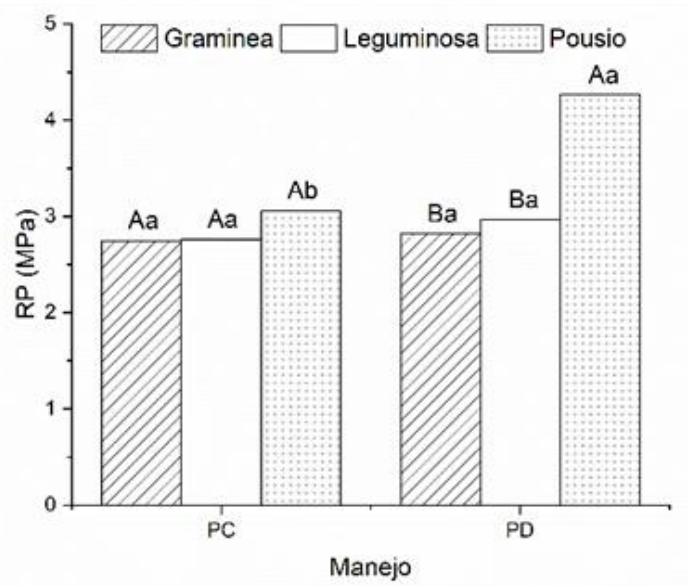

Figura 13. Teor médio de Resistência à penetração média, RP, para as coberturas avaliadas (gramínea, leguminosa e pousio) em ambos os manejos (PD e PC). Letras minúsculas comparam os manejos dentro de cada cobertura e letras maiúsculas comparam as coberturas dentro de cada manejo pelo teste de Tukey ao nível de 5\% de significância. 


\subsection{Porosidade total, $\beta$}

Para porosidade total o fator que está influenciando as diferenças nos níveis resultantes deste atributo é a cobertura, sendo a leguminosa a que obteve diferença significativa $(p \leq 0,05)$, figura 14 .

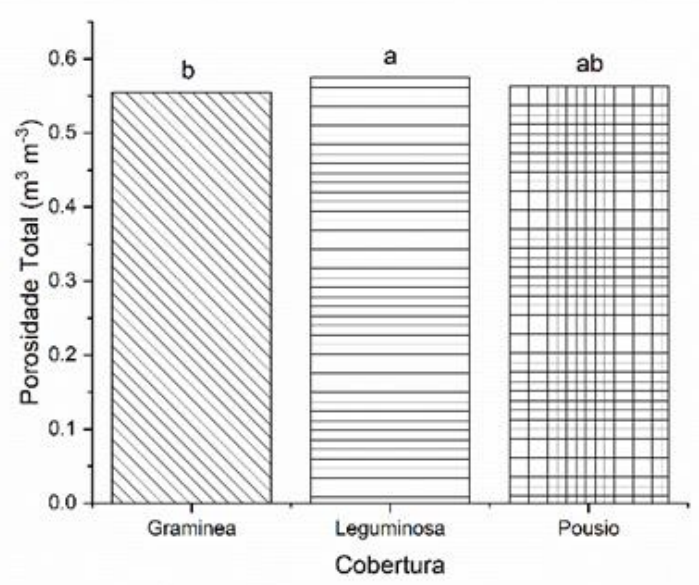

Figura 14. Porosidade total médio para as coberturas avaliadas (gramínea, leguminosa e pousio). Letras comparam e demonstram as diferenças dos valores apresentados para o fator significante, determinado pelo teste Tukey a 5\%.

\subsection{Intervalo de água disponível, IAD}

A partir dos resultados obtidos para médias de IAD, é possível observar que tanto o manejo (figura 15) como a cobertura (figura 16) influenciam seus níveis, porém, não houve interação significativa entre eles ( $\mathrm{p} \leq 0,05)$, ou seja, os fatores são independentes, sendo que PC diferenciou-se de PD apresentando maior média com relação às coberturas, a que se diferenciou das demais com maior média foi a do tipo gramínea. 


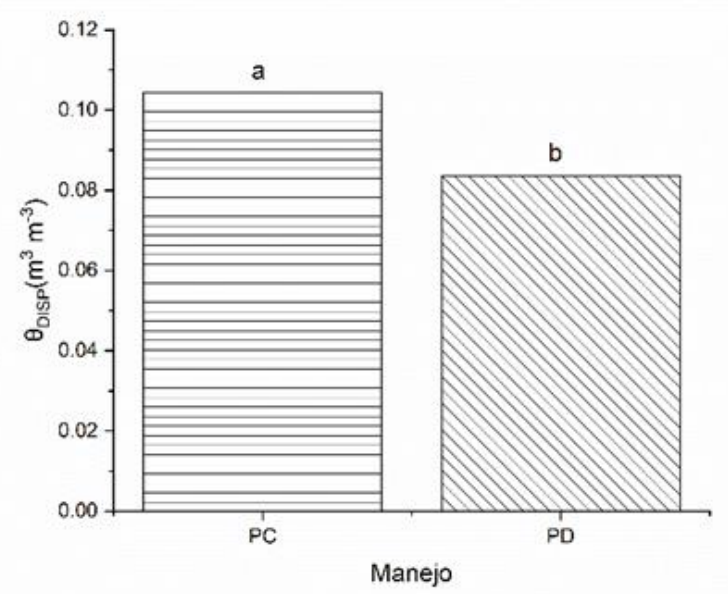

Figura 15. Teor médio de intervalo de água disponível, IAD, para os manejos avaliados (PC e PD). Letras comparam e demonstram as diferenças dos valores apresentados para o fator significante, determinado pelo teste Tukey a $5 \%$.

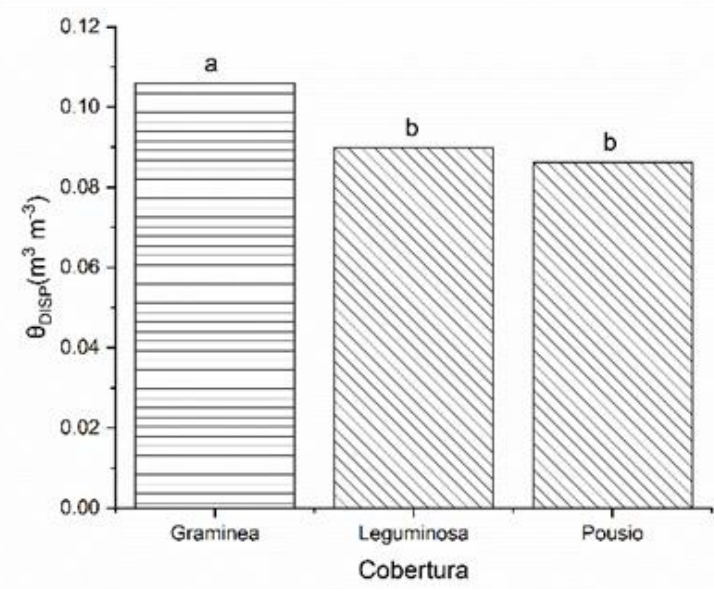

Figura 16. IAD para as coberturas avaliadas (gramínea, leguminosa e pousio). Letras comparam e demonstram as diferenças dos valores apresentados para o fator significante, determinado pelo teste Tukey a 5\%.

\subsection{Ajuste das CRA's}

Com o intuito de verificar se o modelo matemático utilizado por van Genutchen (1980) (equação 6) para ajustar os dados das CRA's, verificou-se que ele foi adequado para o solo deste estudo. Foram analisados os parâmetros gerados pelo ajuste: coeficiente de determinação $\mathrm{R}^{2}$ (equação 15), que equivale a uma correlação entre os dados observados e os dados preditos, em conjunto ao coeficiente de correlação de Pearson, $r$ (equação 16) e a raiz quadrada do erro médio, RMSE (equação 17). 


$$
R^{2}=\frac{\left[n \sum \theta o \theta e-\left(\sum \theta o\right)\left(\sum \theta e\right)\right]^{2}}{\left[n \sum \theta o^{2}-\left(\sum \theta o\right)^{2}\right]\left[n \sum \theta e^{2}-\left(\sum \theta e\right)^{2}\right]}
$$

$$
r=\sqrt{R^{2}}
$$

$$
R M S E=\sqrt{\frac{1}{n} \sum_{i=1}^{n}\left(\theta_{e}-\theta_{0}\right)^{2}}
$$

Nas equações (15) e (17), $\theta_{\mathrm{e}}$ e $\theta_{0}$ representou os conteúdos de água volumétricos estimado e observado, respectivamente.

Os resultados obtidos confirmam que o modelo pode ser utilizado para quase todos os tipos de solos (Yang e You, 2013), incluindo os de textura muita argilosa como o que foi objeto de estudo, mostrando, enfim, que a escolha deste ajuste foi adequada em razão dos valores de $\mathrm{R}^{2}$ muito próximos a 1 e de RMSE a 0 (tabelas 8, 9 e 10). 
Tabela 8. Parâmetros de ajuste da equação (6) para gramínea.

\begin{tabular}{cccccccc}
\hline Profundidade & \multicolumn{1}{c}{$\theta_{\mathrm{r}}$} & $\theta_{\mathrm{s}}$ & $\alpha$ & $\mathrm{n}$ & $\mathrm{m}$ & $\mathrm{R}^{2}$ & RMSE \\
\cline { 2 - 6 } $\mathrm{m}^{3} \mathrm{~m}^{-3}-$ & $\begin{array}{c}\mathrm{kPa}^{-1} \\
\text { Direto }\end{array}$ \\
$0,00-0,05$ & 0.265 & 0.565 & 0.536 & 1.500 & 0.333 & 0.998 & 0.000 \\
$0,05-0,10$ & 0.188 & 0.494 & 3.672 & 1.161 & 0.139 & 0.997 & 0.000 \\
$0,10-0,20$ & 0.252 & 0.491 & 0.794 & 1.315 & 0.240 & 0.997 & 0.000 \\
$0,20-0,30$ & 0.234 & 0.494 & $\begin{array}{c}1.265 \\
\text { Convencional }\end{array}$ & 1.298 & 0.229 & 0.999 & 0.000 \\
$0,00-0,05$ & 0.249 & 0.598 & 0.610 & 1.502 & 0.334 & 0.995 & 0.000 \\
$0,05-0,10$ & 0.200 & 0.571 & 2.587 & 1.287 & 0.223 & 0.997 & 0.000 \\
$0,10-0,20$ & 0.248 & 0.541 & 0.762 & 1.402 & 0.287 & 0.993 & 0.000 \\
$0,20-0,30$ & 0.250 & 0.541 & 1.736 & 1.258 & 0.205 & 0.994 & 0.000 \\
\hline
\end{tabular}

Tabela 9. Parâmetros de ajuste da equação (6) para leguminosa.

\begin{tabular}{|c|c|c|c|c|c|c|c|}
\hline Profundidade & $\theta_{\mathrm{r}}$ & $\theta_{\mathrm{s}}$ & $\alpha$ & $\mathrm{n}$ & $\mathrm{m}$ & $\mathrm{R}^{2}$ & RMSE \\
\hline \multirow[t]{2}{*}{$\mathrm{m}$} & \multirow{2}{*}{\multicolumn{2}{|c|}{$\mathrm{m}^{3} \mathrm{~m}^{-3}$}} & $\mathrm{kPa}^{-1}$ & & & & \\
\hline & & & Direto & & & & \\
\hline $0,00-0,05$ & 0.226 & 0.522 & 1.125 & 1.466 & 0.318 & 0.994 & 0.000 \\
\hline $0,05-0,10$ & 0.247 & 0.526 & 0.722 & 1.532 & 0.347 & 0.994 & 0.000 \\
\hline $0,10-0,20$ & 0.220 & 0.495 & 1.128 & 1.430 & 0.301 & 0.994 & 0.000 \\
\hline $0,20-0,30$ & 0.244 & 0.531 & 2.258 & 1.355 & 0.262 & 0.910 & 0.000 \\
\hline \multicolumn{8}{|c|}{ Convencional } \\
\hline $0,00-0,05$ & 0.263 & 0.591 & 0.871 & 1.548 & 0.354 & 0.990 & 0.000 \\
\hline $0,05-0,10$ & 0.248 & 0.573 & 1.101 & 1.373 & 0.272 & 0.990 & 0.000 \\
\hline $0,10-0,20$ & 0.228 & 0.585 & 1.283 & 1.491 & 0.329 & 0.994 & 0.000 \\
\hline $0,20-0,30$ & 0.251 & 0.555 & 1.107 & 1.362 & 0.266 & 0.988 & 0.000 \\
\hline
\end{tabular}

Tabela 10. Parâmetros de ajuste da equação (6) para pousio.

\begin{tabular}{|c|c|c|c|c|c|c|c|}
\hline Profundidade & $\theta_{\mathrm{r}}$ & $\theta_{\mathrm{s}}$ & $\alpha$ & $\mathrm{n}$ & $\mathrm{m}$ & $\mathrm{R}^{2}$ & RMSE \\
\hline \multirow[t]{2}{*}{$\mathrm{m}$} & \multirow{2}{*}{\multicolumn{2}{|c|}{$\mathrm{m}^{3} \mathrm{~m}^{-3}$}} & $\mathrm{kPa}^{-1}$ & & & & \\
\hline & & & Direto & & & & \\
\hline $0,00-0,05$ & 0.292 & 0.549 & 0.736 & 1.511 & 0.338 & 0.983 & 0.000 \\
\hline $0,05-0,10$ & 0.265 & 0.542 & 1.048 & 1.337 & 0.252 & 0.977 & 0.000 \\
\hline $0,10-0,20$ & 0.304 & 0.537 & 1.088 & 1.550 & 0.355 & 0.984 & 0.000 \\
\hline $0,20-0,30$ & 0.278 & 0.500 & 0.724 & 1.322 & 0.244 & 0.994 & 0.000 \\
\hline \multicolumn{8}{|c|}{ Convencional } \\
\hline $0,00-0,05$ & 0.217 & 0.536 & 1.064 & 1.372 & 0.271 & 0.993 & 0.000 \\
\hline $0,05-0,10$ & 0.202 & 0.542 & 1.346 & 1.305 & 0.234 & 0.981 & 0.000 \\
\hline $0,10-0,20$ & 0.231 & 0.546 & 0.734 & 1.512 & 0.338 & 0.996 & 0.000 \\
\hline $0,20-0,30$ & 0.234 & 0.544 & 0.538 & 1.550 & 0.355 & 0.995 & 0.000 \\
\hline
\end{tabular}




\subsection{Curvas de retenção da água no solo, CRA}

As CRA's obtidas encontram-se dispostas na figura 17.
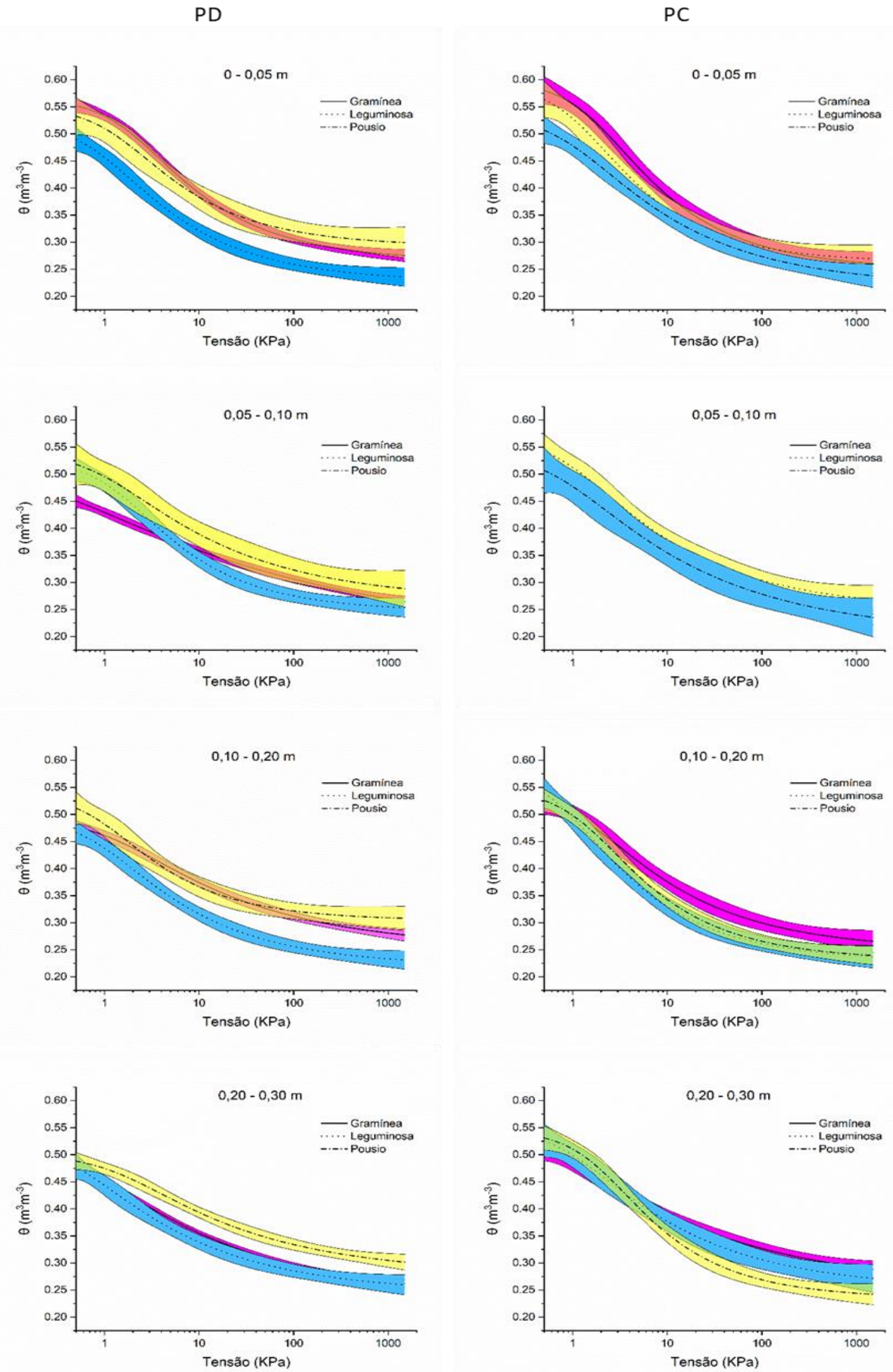

Figura 17. Curvas de Retenção de Água no Solo, CRA's, obtidas pelo ajuste da equação (6). 


\subsection{Distribuição de poros e porosidade total, $\theta_{\mathrm{s}}$}

Os gráficos que mostram a distribuição de poros nas classes micro, macro, e mesoporosidade bem como a porosidade total, este último também considerado como o

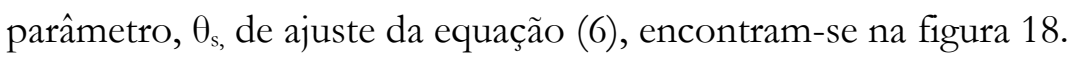

PD

A

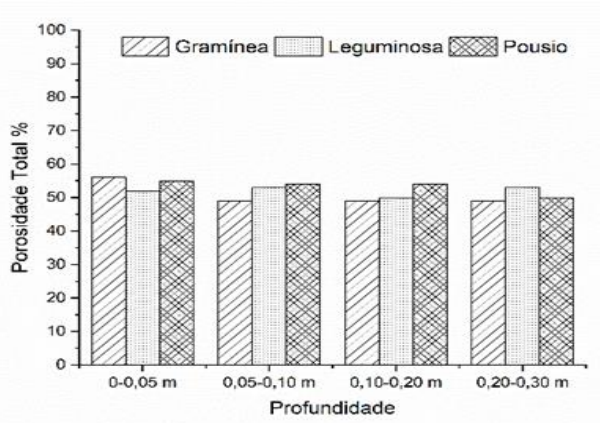

B

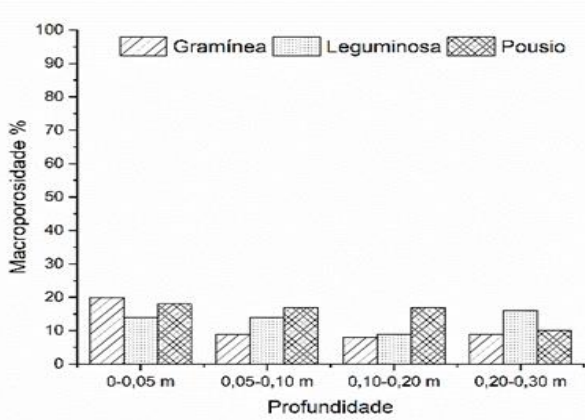

$\mathrm{C}$

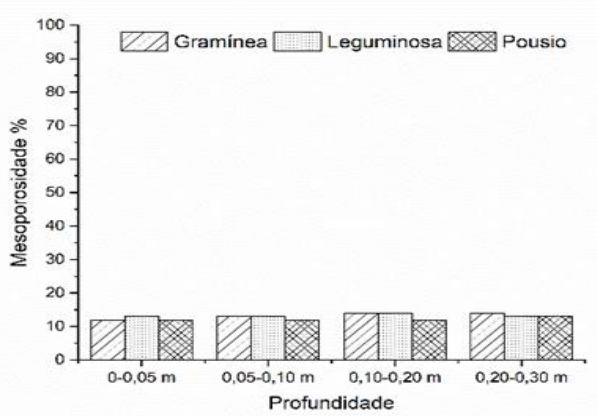

$\mathrm{D}$

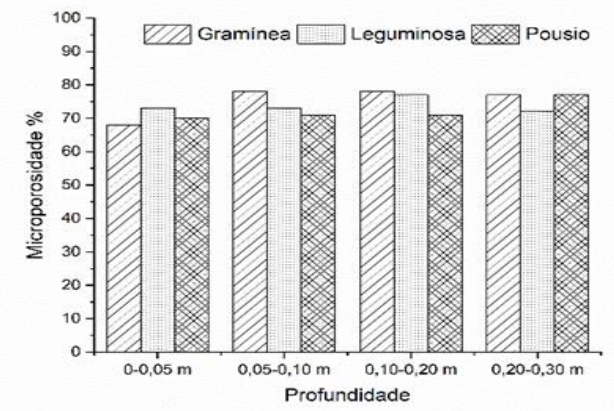

$\mathrm{PC}$

E
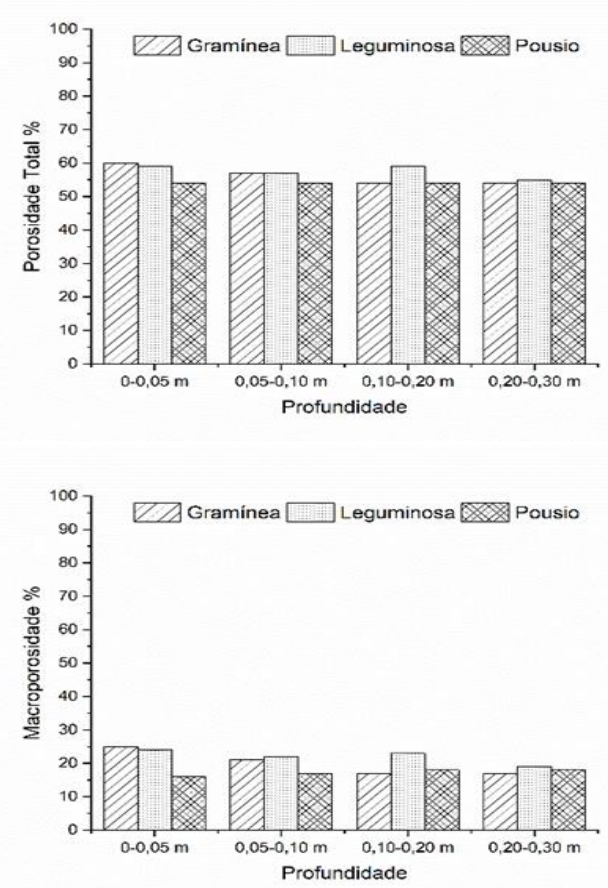

G

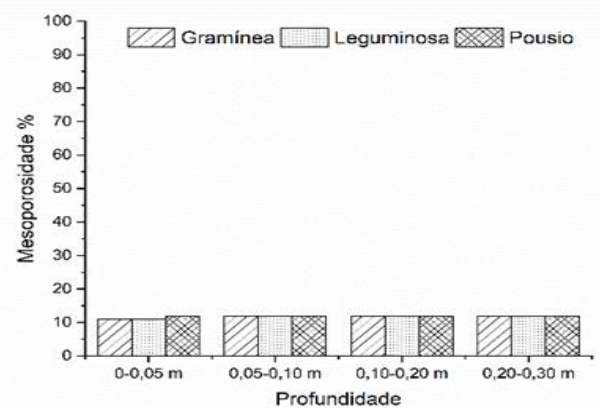

$\mathrm{H}$

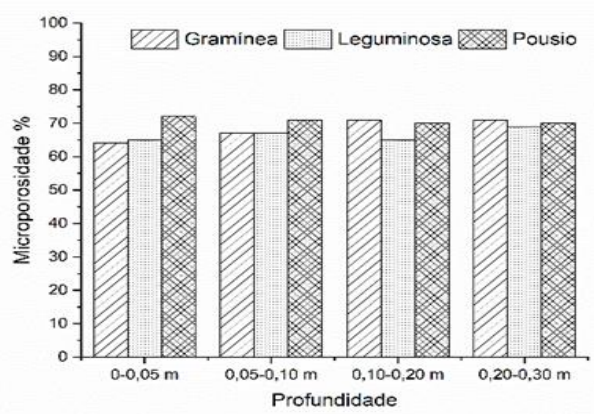

Figura 18. Distribuição de poros (macro, micro e macroporos) e porosidade total $\left(\theta_{\mathrm{s}}\right)$. 


\subsection{Curvas da frequência de raios dos poros}

As curvas obtidas a partir da equação resultante da diferenciação da equação (6), isto é, as curvas diferenciais das CRA's e que resultam na curva da frequência de raios dos poros encontram-se dispostas na figura 19, na qual consta também indicados em cada curva os pontos referentes ao valor do raio de maior frequência.

PD

A

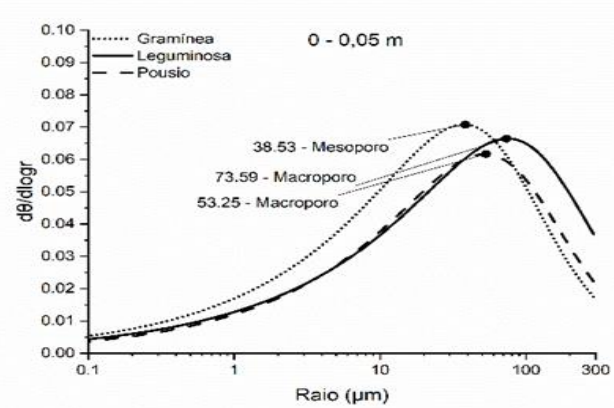

B

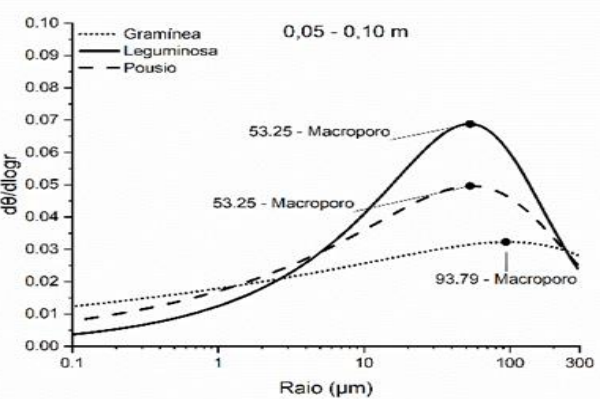

$\mathrm{C}$

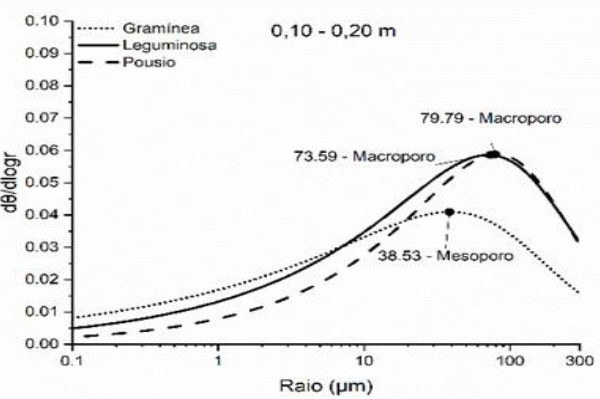

$\mathrm{D}$

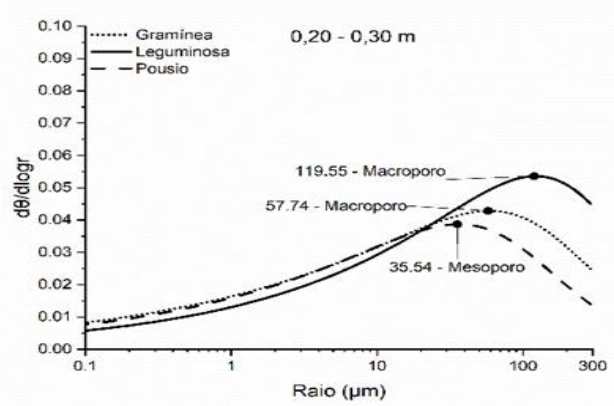

PC

$\mathrm{E}$

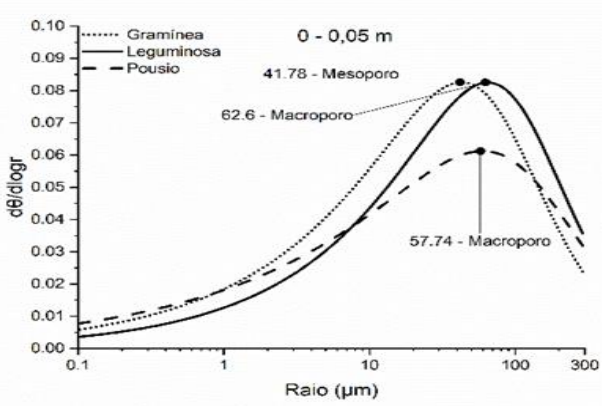

F

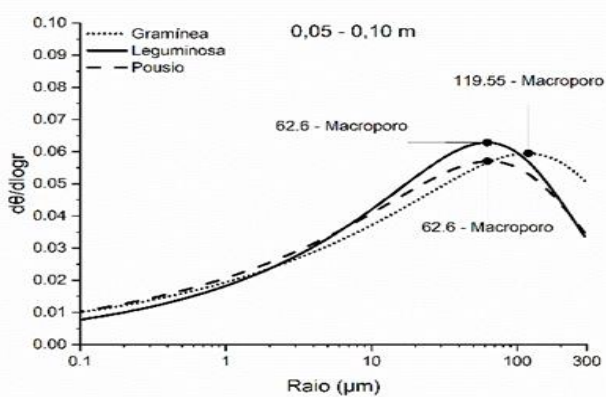

G

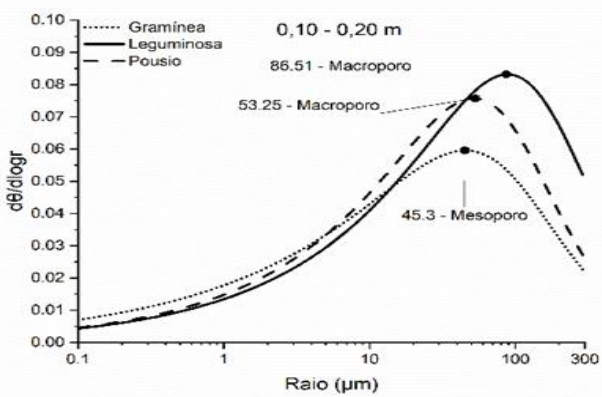

H

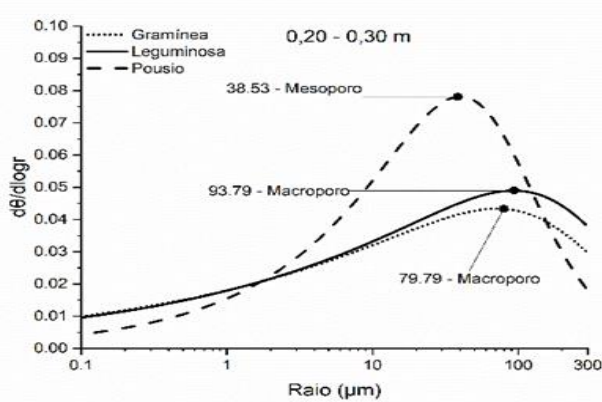

Figura 19. Curvas da frequência de raios dos poros. 


\subsection{Condutividade hidráulica relativa, $\mathrm{K}_{\mathrm{r}}$}

As curvas obtidas para $K_{r}$ a partir da equação (14), para os doismanejos, as três coberturas e a quatro profundidades do solo estão expressas na figura 20.

PD
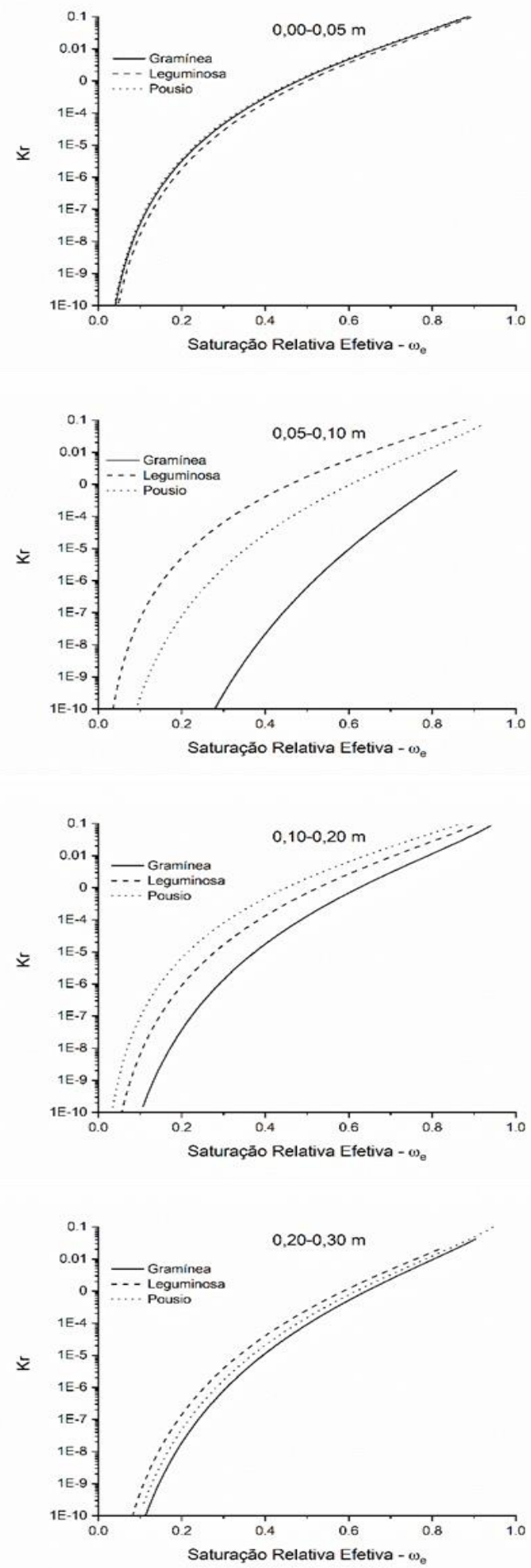

PC
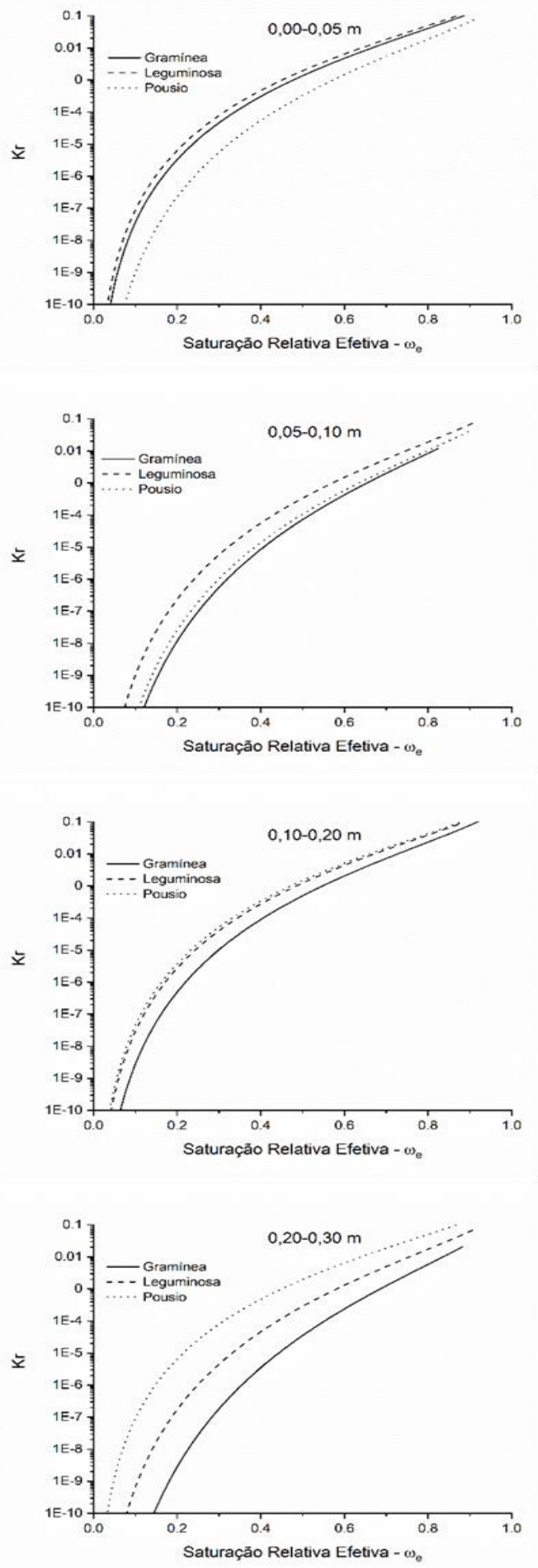

Figura 20. Gráficos da função condutividade hidráulica relativa do solo $K_{r}(\theta)$. 


\section{DISCUSSÃO}

A parte mais úmida da CRA é aquela sob maior influência da porosidade estrutural do solo e mostra como a forma da curva está ligadada ao fenômeno da retenção da água no solo, a qual ocorre principalmente pela ação das forças mátricas da capilaridade. Já na região em que a CRA é suavemente descrescente, ou seja, nos pontos de menor conteúdo de água e maior tensão, a textura do solo é o fenômeno que deve ser o mais determinante para a retenção principalmente por adsorção (Libardi, 2018).

As CRA's dos manejos PD e PC (figura 17) apresentaram algumas diferenças, sendo que as do PC (figura 17-E, F, G, H) apresentaram valores de $\theta$ um pouco maiores que os encontrados em PD (figura 17-A, B, C, D). Ainda, o PC apresentou pouca diferença entre valores de $\theta$ para diferentes coberturas a uma mesma profundidade. Em PD a cobertura do tipo gramínea foi a que mais reteve água na camada superficial $(0,00-0,05 \mathrm{~m})$ e a cobertura do tipo leguminosa foi a que menos reteve água na maioria das profundidades avaliadas, sendo possível observar que para a parte mais seca da curva os menores valores de $\theta$ são atribuídos a esta cobertura; isto pode significar que o tratamento possa estar facilitando o movimento da água tornando o solo mais seco, o contrário ocorrendo com a gramínea. O gráfico da figura 15 e 16 estão de acordo com esta hipótese, pois por eles pode-se notar que a maior média de IAD é encontrada para as gramíneas. Com relação a maior média de IAD encontrada para o PC (figura 15) será explicado mais adiante.

Visto que um solo bem estruturado possui muitos agregados e que a sua formação não depende somente do manejo, depende também da microbiota e das espécies cultivadas que alteram de forma complexa o sistema poroso do solo (SPS) pelo poder de penetração de raízes, extração de água, exsudação e fixação de componentes pela rizosfera, os efeitos serão diferentes em função dos diversos tipos de sistema radicular existentes (Tisdall e Oades, 1982; Materechera et al., 1991). E esta pode ser uma das razões pelas diferenças encontradas com o uso de gramíneas e leguminosas, pois suas raízes se diferenciam morfologicamente. As plantas do tipo leguminosa possuem raíz pivotante e atingem maior profundidade no perfil do solo, tendo menor número de raízes, são verticais e de maior calibre, enquanto que as raízes das gramíneas se desenvolvem mais superficialmente, sendo todas de calibre menor, numerosas e com crescimento em todas as direções, daí serem denominadas fasciculadas. Poros criados em decorrência do crescimento de raízes, geralmente são classificados como macroporos (Gibbs e Reid, 1988) e, apesar de as raízes do tipo pivotante favorecem o fluxo de água em macroporos, isto foi 
observado de maneira mais expressiva para aquelas em processo de decomposição (Caron et al., 1996; Mitchell et al., 1995), além de que as raízes fasciculadas também podem contribuir para o aumento da macroporosidade, e da formação de macroagregados conforme comprovado por (Rasse et al., 2000).

Acredita-se que o PC apresentou melhores níveis de retenção de água e de IAD (figura 15) pelo fato deste sistema ter sido recentemente implementado, demonstrando que a quebra do PD, pelo revolvimento do solo foi benéfica neste primeiro momento, gerando maior aeração, aumento da macroporosidade (figura 18) e, em consequência disto, maior retenção de água. Porém, não se pode afirmar que este sistema de manejo é o mais indicado, pois sua prática pode ocasionar maior quebra de agregados, significando que, apesar de aumentar a porosidade do solo, pode se encontrar menos estruturado pela destruição dos agregados e da conectividade do SPS, tornando o solo pulverizado, conforme sugere o trabalho de Moraes et al. (2016). Ainda, as mudanças nas propriedades físicas do solo em razão do seu cultivo não são permanentes, tendem a variar com o tempo, atingindo valores próximos aos obtidos anteriormente às operações de plantio, conforme descreve (Ahuja et al., 1998) pelo estudo que objetivou comparar as diferenças encontradas para as CRA's de um solo recém cultivado em relação a este mesmo solo em condição anterior ao seu cultivo.

Como característica intrínseca, a textura do solo pode indicar apenas de forma geral a distribuição dos poros de um solo. Para um solo como o utilizado neste estudo, de textura argilosa a muito argilosa, é comum obter-se maior proporção para poros classificados como microporos, ou seja, aqueles com diâmetro $<30 \mu \mathrm{m}$. E pela (figura 18) é possível perceber que os maiores valores, independentemente do sistema de manejo e da cobertura, são os de microporosidade. Porém, em uma análise mais detalhada é possível perceber uma tendência para maiores valores de macroporosidade para o sistema de PC, principalmente, na camada mais superficial, estando isto provavelmente ligado às operações realizadas para a implementação do sistema, as quais haviam sido recém realizadas à coleta das amostras para realização deste estudo.

A partir das informações obtidas pelas CRA's ajustadas e assumindo que $\theta_{\mathrm{s}}=\beta=$ porosidade do solo, os valores de $\beta$ para PD e PC (tabelas 3,4, e 5 e figuras 18 A e B) não foram significativamente diferentes, embora seja possível perceber que os valores no PC foram um pouco superiores em relação ao PD em todas as profundidades para as coberturas gramínea e leguminosa. Nota-se que também para a cobertura leguminosa no PC, os valores foram superiores ao do pousio em todas as profundidades e para a cobertura gramínea superiores ao do pousio em todas as profundidades e para a cobertura gramínea superiores ao do pousio para as duas profundidades mais superficiais. Considerando agora as classes macroporos, mesoporos e 
microporos, percebe-se um incremento de macroporos (figura 18-B e F) para todas as coberturas em todas as profundidades do PC em relação ao PD. Já a mesoporosidade (figura 18-C e G) praticamente não se percebe variação provavelmente devido à quebra do PD em todas as profundidades. E finalmente, para a microporosidade (figura 18-D e H) as porcentagens para PC diminuíram em relação a PD, significando, possivelmente, que houve uma desestruturação, o que gera maior descontinuidade do SPS.

Para os gráficos da figura 19, percebe-se que a distribuição da frequência dos poros foi semelhante para os manejos PD e PC, porém, quando se atenta aos valores de raio do poro mais frequente (o pico da curva), nota-se que, de um modo geral, para todas as camadas e coberturas os poros de raio de maior frequência possuem a mesma classificação, estando apresentados como macro ou mesoporo, apesar de diferirem em tamanho. Nota-se, a partir das figuras 18 e 19, que apesar do solo estudado possuir a maior porcentagem de seus poros classificados como microporos, os raios de maior frequência são os macroporos. Isto pode ser explicado principalmente pela diferença entre porosidade estrutural e textural, sendo que a textural é aquela que diz respeito ao arranjo das partículas primárias constituintes do solo, e que não sofrem influência direta pela compactação ou pelo manejo empregado, diferentemente da porosidade estrutural, a qual resulta das atividades biológicas e das de cultivo, tráfego, e condições climáticas (Monnier et al., 1973; Richard et al., 2001).

A condutividade hidráulica do solo em função do conteúdo de água no solo, $\mathrm{K}_{\mathrm{r}}(\theta)$, a qual é estimada a partir dos parâmetros ajustados da CRA, $\alpha, \mathrm{m}$ e $\mathrm{n}$ (ver equação 14) dá informação sobre o comportamento hidráulico do solo estudado. A capacidade de retenção de água no solo depende diretamente da estrutura e porosidade do solo, logo a função $K_{r}(\theta)$ também possuem relação com a estrutura e porosidade do solo, pois trata-se de um coeficiente que expressa a facilidade com que um fluído é transportado através de um meio poroso. Portanto, quanto maior quantidade de macroporos de um solo, maior deverá ser sua condutividade hidráulica quando saturado. Pelas curvas da figura 20, ve-se, no entanto, que a cobertura com a qual foram obtidos os maiores valores da saturação relativa efetiva $\left(\omega_{\mathrm{r}}\right)$ para uma dada $\mathrm{K}_{\mathrm{r}}$, foi a do tipo gramínea, indicando que tal cobertura possa estar contribuindo para uma maior retenção de água pela matriz do solo, na condição de não saturação visto que sua $K_{\mathrm{r}}$ é a menor para um dado valor de $\omega_{\mathrm{e}}<1$, o inverso devendo ocorrer na saturação. Rasse et al (2000) encontraram, inclusive, aumento de $57 \%$ para condutividade hidráulica do solo saturado com a utilização de uma planta do tipo gramínea (Medicago sativa) como cobertura, comprovando a teoria de que a condutividade hidráulica do solo saturado é sensível a porosidade (Carof et al., 2007), pois uma pequena redução na porosidade de um solo por um mal manejo resulta em grande redução na condutividade. Ao 
passo que, o aumento da agregação mantendo os níveis de porosidadecom um bom manejo resulta em incremento positivo de condutividade. Portanto, é lógico dizer que a desagregação do solo resulta em quedas substanciais dos índices de condutividade (Kutílek e Nielsen, 1994).

Porém, para as camadas superficiais, onde ocorrem alterações perante manejo empregado, observa-se que PD com cobertura do tipo gramínea apresenta o maior nível percentual de C, significando que a escolha do tipo de planta cultivada possui influência na quantidade de $\mathrm{C}$ armazenada pelo solo, ou seja, plantas do tipo gramínea possuem maior efeito e contribuem de forma mais significativa para o estoque de carbono pelo solo, o que é considerado como um serviço ecossistêmico (Adhikari e Hartemink 2016; Swinton et al. 2006)

Os valores obtidos para APDA (figura 9) e AMDA (figura 10 e 11) estão de acordo com o esperado. Eles variaram no perfil do solo a profundidade, sendo que para APDA o efeito de manejo não foi observado, porém para AMDA é possível observar (figura 10) que para o PD houve diferença significativa de suas media maior quando comparada ao PC. Fuller et al (1995) definiram que a dispersibilidade da argila está diretamente relacionada ao conteúdo de carbono, e ao compararmos os resultados de AMDA com os de C Total (figura 12) é possível perceber que estes possuem correlação inversa, ou seja, quanto maior o conteúdo de $\mathrm{C}$, menor a quantidade de argila dispersa, logo o PD por longo período resultou em decréscimo na energia requerida para dispersar a argila, encontrada principalmente nos agregados do solo. Portanto, a atividade agrícola exercida neste solo resultou em agregados mais frágeis e susceptíveis a dispersão, podendo resultar em um solo propenso a erosão e ao encrostamento superficial (Getahun et al., 2016; Nunes et al., 2017; Obour et al., 2018).

Os índices obtidos pela avaliação de RP (figura 13) mostram que o solo da área sob PD encontra-se compactado, considerando que a força que as raízes exercem durante crescimento pode chegar a $2 \mathrm{MPa}$ (Goss, 1991), e isto é mais evidente ainda para as áreas em pousio, as quais sofreram maior efeito do adensamento, indicando, por outro lado, que a atividade das raízes de plantas cultivadas é de fato benéfica à estrutura do solo, com capacidade de aumentar a porosidade e consequentemente aeração, reduzindo níveis de compactação, independentemente do tipo de raiz das plantas (Carof et al., 2007). Ainda, o consumo de água pelas plantas aumenta a capacidade do solo em se manter coeso (Lafond et al., 1992), visto que a RP é inversamente proporcional ao conteúdo de água, o que explica o fato de alguns solos possuírem estrutura mais estável do que solos sem cultivo, mesmo se estes apresentam maiores valores para conteúdo de água, como é o caso do solo em pousio do PC. Além do consumo uso de água pelas plantas, que diminue o conteúdo de água no solo, as raízes aumentam a estabilidade estrutural do solo por 
meio de outros mecanismos como a produção e liberação de exsudatos, principalmente observados na rizosfera (Angers e Caron 1998; Morel et al. 1991). 


\section{CONCLUSÃO}

Por este trabalho é possível concluir que a implantação do sistema de plantio convencional proporcionou aumento nos níveis de macroporosidade, e que a cobertura do tipo gramínea foi a que obteve melhores resultados para a retenção de água no solo. Também concluí-se que o intervalo de água disponível, IAD, foi maior para a cobertura do tipo gramínea. Já a resistência a penetração no PD foi maior do que em PC. E o conteúdo de C também apresentou valores maiores em PD. Porém, através dos resultados de AMDA e APDA, nota-se que o solo sob PC encontra-se desestruturado. 


\section{CONSIDERAÇÕES FINAIS}

A partir da análise dos resultados das curvas de retenção, é possível observar que o manejo altera, de fato, a estrutura do solo e que uma área cultivada por um longo período sob plantio direto pode se encontrar compactada, com níveis acima do recomendado, mesmo que esta condição não tenha apresentado impedimento para o desenvolvimento das plantas cultivadas. Com relação ao tipo de manejo, é possível inferir que a utilização do plantio convencional pode proporcionar maior aeração do solo pelo incremento da porosidade, o que é vantajoso para o desenvolvimento do sistema radicular. Porém, estudos que avaliem a duração dos efeitos benéficos da quebra de um plantio direto consolidado pelas operações de cultivo do plantio convencional devem ser realizados, a fim de compreender melhor a variabilidade temporal acerca da implantação deste sistema, para assim definir um cronograma ideal de sua aplicação em conjunto ao sistema de plantio direto. Outro resultado encontrado, é que as plantas de cobertura do tipo gramínea apresentaram maior vantagem em relação às leguminosas, visto que se verificou possuírem maior poder de estruturar os solos, o que deve estar ligado a morfologia de suas raízes. 


\section{REFERÊNCIAS}

Adhikari, K., Hartemink, A.E. (2016) Linking soils to ecosystem services - A global review. Geoderma, 262:101-111. doi:10.1016/j.geoderma.2015.08.009

Ahuja, L.R., Fiedler, F., Dunn, G.H., Benjamin, J.G., Garrison, A. (1998) Changes in soil water retention curves due to tillage and natural reconsolidation. Soil Sci. Soc. Am. J., 62:12281233. doi:10.2136/sssaj1998.03615995006200050011x

Alaoui, A., Lipiec, J., Gerke, H.H. (2011) A review of the changes in the soil pore system due to soil deformation: A hydrodynamic perspective. Soil Till. Res., 115-116:1-15. doi:10.1016/j.still.2011.06.002

Angers, D.A., Caron, J. (1998) Plant-induced changes in soil structure: Processes and feedbacks. Biogeochemistry, 42:55-72. doi:10.1023/A:1005944025343

Auler, A.C., Miara, S., Pires, L.F., Fonseca, A.F., Barth, G. (2014) Soil physico-hydrical properties resulting from the management in integrated production systems. Rev. Ciênc. Agron., 45:976-989. doi:10.1590/S1806-66902014000500013

Bayer, C., Mielniczuk, J., Amado, T.J.C., Martin-Neto, L., Fernandes, S.V. (2000) Organic matter storage in a sandy clay loam acrisol affected by tillage and cropping systems in southern Brazil. Soil Till. Res., 54:101-109. doi:10.1016/S0167-1987(00)00090-8

Blanco-Canqui, H., Mikha, M.M., Presley, D.R., Claassen, M.M. (2011) Addition of cover crops enhances no-till potential for improving soil physical properties. Soil Sci. Soc. Am. J., 75:1471-1482. doi:10.2136/sssaj2010.0430

Blum, W.E.H. (2005) Functions of soil for society and the environment. Rev. Environ. Sci. Biotechnol., 4:75-79. doi:10.1007/s11157-005-2236-x

Bouma, J., Anderson, J.L. (1973) Relationships between soil structure characteristics and hydraulic conductivity. In: Bruce, R.R., Flach, K.W., Taylor, H.W. (Ed.), Field Soil Water Regime. SSSA Spec. Publ. 5, SSSA, Madison, p.77-105. doi:10.2136/sssaspecpub5.c5

Bradford, J.M. (1986) Penetrability. In: Klute, A. (Ed.), Methods of Soil Analysis. Part 1 Physical and Mineralogical Methods. SSSA Book Series, SSSA, Madison, p.463-478. doi:10.2136/sssabookser5.1.2ed.c19

Brady, N.C., Weil, R.R. (2008) The nature and properties of soil. 14ed. Prentice-Hall, Upper Saddle River. 975p.

Bridges, E.M., Oldeman, L.R. (1999) Global assessment of human-induced soil degradation. Arid Soil Res. Rehab., 13:319-325. doi:10.1080/089030699263212 
Brooks, R.H., Corey, A.T. (1964) Hydraulic Properties of porous media. Hydrol. Pap. 3, Civ. Eng. Dep., Colo. State Univ., Fort Collins. 27p.

Busscher, W.J. (1990) Adjustment of flat-tipped penetrometer resistance data to a coomon water content. Transactions of the ASAE, 33:519-524. doi:10.13031/2013.31360

Camara, R.K., Klein, V.A. (2005) Propriedades físico-hídricas do solo sob plantio direto escarificado e rendimento da soja. Ci. Rural, 35:813-819. doi:10.1590/S010384782005000400010

Campbell, G.S. (1974) A Simple Method for Determining Unsaturated Conductivity from Moisture Retention Data. Soil Sci., 117:311-314. doi:10.1097/00010694197406000-00001

Carof, M., Tourdonnet, S., Coquet, Y., Hallaire, V., Roger-Estrade, J. (2007) Hydraulic conductivity and porosity under conventional and no-tillage and the effect of three species of cover crop in northern France. Soil Use and Manag., 23:230-237. doi:10.1111/j.14752743.2007.00085.x

Caron, J., Espindola, C.R., Angers, D.A. (1996) Soil structural stability during rapid wetting: Influence of land use on some aggregate properties. Soil Sci. Soc. Am. J., 60:901-908. doi:10.2136/sssaj1996.03615995006000030032x

Carter, M.R. (1990) Relative measures of soil bulk density to characterize compaction in tillage studies on fine sandy loams. Can. J. Soil Sci., 70:425-433. doi:10.4141/cjss90-042

Castellini, M., Pirastru, M., Niedda, M., Ventrella, D. (2013) Comparing physical quality of tilled and no-tilled soils in an almond orchard in southern Italy. Ital. J. Agron., 8:149-157. doi:10.4081/ija.2013.e20

Çerçioğlu, M., Anderson, S.H., Udawatta, R.P., Alagele, S. (2019) Effect of cover crop management on soil hydraulic properties. Geoderma, 343:247-253. doi:10.1016/j.geoderma.2019.02.027

Chamen, T., Alakukku, L., Pires, S., Sommer, C., Spoor, G., Tijink, F., Weisskopf, P. (2003) Prevention strategies for field traffic-induced subsoil compaction: a review: Part 2. Equipment and field practices. Soil Till. Res., 73:161-174. doi:10.1016/S01671987(03)00108-9

Crestana, S., Vaz, C.M.P. (1998) Non-invasive instrumentation opportunities for characterizing soil porous systems. Soil Till. Res., 47:19-26. doi:10.1016/S0167-1987(98)00068-3

Crusciol, C.A.C., Cottica, R.L., Lima, E.V., Andreotti, M., Moro, E., Marcon, E. (2005) Persistência de palhada e liberação de nutrientes do nabo forrageiro no plantio direto. Pesq. Agropec. Bras., 40:161-168. doi:10.1590/S0100-204X2005000200009 
Derpsch, R., Sidiras, N., Roth, C.H. (1986) Results of studies made from 1977 to 1984 to control erosion by cover crops and no-tillage techniques in Paraná, Brazil. Soil Till. Res., 8:253-263. doi:10.1016/0167-1987(86)90338-7

Dexter, A.R. (2004) Soil physical quality: Part II. Friability, tillage, tilth and hard-setting. Geoderma, 120:215-225. doi:10.1016/j.geoderma.2003.09.005

Doran, J.W., Parkin, T.B. (1994) Defining and assessing soil quality. In: Doran, J.W., Coleman, D.C., Bezdicek, D.F., Stewart, B.A. (Ed.), Defining soil quality for a sustainable environment. SSSA Spec. Publ. 35, SSSA, Madison, p.3-21. doi:10.2136/sssaspecpub35.c1

Doran, J.W., Parkin, T.B. (1996) Quantitative indicators of soil quality: A minimum data set. In: Doran, J.W., Jones, A.J. (Ed.), Methods for assessing soil quality. SSSA Spec. Publ. 49, SSSA, Madison, p.25-27. doi:10.2136/sssaspecpub49.c2

Edwards, J.H., Thurlow, D.L., Eason, J.T. (1988) Influence of tillage and crop rotation on yields of corn, soybean, and wheat. Agron. J., 80:76-80. doi:10.2134/agronj1988.00021962008000010018x

Ferreira, A.C.B., Lamas, F.M., Carvalho, J.M.C.S., Salton, C., Suassuna, N.D. (2010) Cover crops biomass production and cotton yield in no-tillage system. Pesq. Agropec. Bras., 45:546-553.

Flint, A.L., Flint, L.E. (2002) Particle density. In: Dane, J.H., Topp, G.C. (Ed.), Methods of soil analysis. Part 4 - Physical methods. SSSA Book Series, SSSA, Madison, p.229-240. doi:10.2136/sssabookser5.4.c10

Franzluebbers, A.J. (2002) Soil organic matter stratification ratio as an indicator of soil quality. Soil Till. Res., 66:95-106. doi:10.1016/S0167-1987(02)00018-1

Fuller, L.G., Goh, T.B., Oscarson, D.W. (1995) Cultivation effects on dispersible clay of soil aggregates. Can. J. Soil Sci., 75:101-107. doi:10.4141/cjss95-013

Getahun, G.T., Munkholm, L.J., Schjønning, P. (2016) The influence of clay-to-carbon ratio on soil physical properties in a humid sandy loam soil with contrasting tillage and residue management. Geoderma, 264:94-102. doi:10.1016/j.geoderma.2015.10.002

Gibbs, R.J., Reid, J.B. (1988) A conceptual model of changes in soil structure under different cropping systems. Volume 8. In: Stewart, B.A. (Ed.), Advances in soil science. SpringerVerlag, New York, p.123-149. doi:10.1007/978-1-4613-8771-8_3

Gonçalves, A.D.M.A., Libardi, P.L. (2013) Análise da determinação da condutividade hidráulica do solo pelo método do perfil instantâneo. Rev. Bras. Ci. Solo, 37:1174-1184. doi:10.1590/S0100-06832013000500007

Goss, M.J. (1991) Consequences of the activity of roots. In: Atkinson, D. (Ed.), Plant root growth - An ecological perspective. Blackwell's Scient. Publ., London, p.171-186. 
Grossman, R.B., Reinsch, T.G. (2002) Bulk density and linear extensibility. In: Dane, J.H., Topp, G.C. (Ed.), Methods of soil analysis. Part 4 - Physical methods. SSSA Book Series, SSSA, Madison, p.201-228. doi:10.2136/sssabookser5.4.c9

Hammel, J.E. (1989) Long-term tillage and crop rotation effects on bulk density and soil impedance in northern Idaho. Soil Sci. Soc. Am. J., 53:1515-1519. doi:10.2136/sssaj1989.03615995005300050036x

Herrick, J.E. (2000) Soil quality: An indicator of sustainable land management? Appl. Soil Eco., 15:75-83. doi:10.1016/S0929-1393(00)00073-1

Herrick, J.E., Whitford, W.G., Soyza, A.G., Van Zee, J.W., Havstad, K.M., Seybold, C.A., Walton, M. (2001) Field soil aggregate stability kit for soil quality and rangeland health evaluations. Catena, 44:27-35. doi:10.1016/S0341-8162(00)00173-9

Hewitt, A., Dominati, E., Webb, T., Cuthill, T. (2015) Soil natural capital quantification by the stock adequacy method. Geoderma, 241-242:107-114. doi:10.1016/j.geoderma.2014.11.014

Hillel, D. (2003) Introduction to Environmental Soil Physics. Elsevier, Amsterdam. 494p.

Karlen, D.L., Wollenhaupt, N.C., Erbach, D.C., Berry, E.C., Swan, J.B., Eash, N.S., Jordahl, J.L. (1994) Long-term tillage effects on soil quality. Soil Till. Res., 32:313-327. doi:10.1016/01671987(94)00427-G

Kay, B.D., Dexter, A.R. (1990) Influence of aggregate diameter, surface area and antecedent water content on the dispersibility of clay. Can. J. Soil Sci., 70:655-671. doi:10.4141/cjss90068

Koorevaar, P., Menelik, G., Kirksen, C. (1999) Elements of soil physics. Developments in Soil Science 13, Elsevier, Amsterdan. 230p.

Kutílek, M., Jendele, L., Panayiotopoulos, K.P. (2006) The influence of uniaxial compression upon pore size distribution in bi-modal soils. Soil Till. Res., 86:27-37. doi:10.1016/j.still.2005.02.001

Kutílek, M., Nielsen, D.R. (1994) Soil hydrology: texbook for students of soil science, agriculture, forestry, geoecology, hydrology, geomorphology and other related disciplines. Catena Verlag, Destedt. 370p.

Lafond, G.P., Loeppky, H., Derksen, D.A. (1992) The effects of tillage systems and crop rotations on soil water conservation, seedling establishment and crop yield. Can. J. Plant Sci., 72:103-115. doi:10.4141/cjps92-011

Lal, R., Reicosky, D.C., Hanson, J.D. (2007) Evolution of the plow over 10,000 years and the rationale for no-till farming. Soil Till. Res., 93:1-12. doi:10.1016/j.still.2006.11.004 
Letey, J. (1985) Relationship between soil physical properties and crop production. Volume 1. In: Stewart, B.A. (Ed.), Advences in soil science. Springer-Verlag, New York, p.277-294. doi:10.1007/978-1-4612-5046-3_8

Libardi, P.L. (2018) Dinâmica da Água no Solo. 3.ed. EDUSP, São Paulo. 346p.

Libardi, P.L., Reichardt, K., Nielsen, D.R., Biggar, J.W. (1980) Simple field methods for estimating soil hydraulic conductivity. Soil Sci. Soc. Am. J., 44:3-7. doi:10.2136/sssaj1980.03615995004400010001x

Logsdon, S.D., Karlen, D.L. (2004) Bulk density as a soil quality indicator during conversion to notillage. Soil Till. Res., 78:143-149. doi:10.1016/j.still.2004.02.003

Materechera, S.A., Dexter, A.R., Alston, A.M. (1991) Penetration of very strong soils by seedling roots of different plant species. Plant and Soil, 135:31-41. doi:10.1007/BF00014776

Matus, A., Derksen, D.A., Walley, F.L., Loeppky, H.A., van Kessel, C. (1997) The influence of tillage and crop rotation on nitrogen fixation in lentil and pea. Can. J. Plant Sci., 77:197-200. doi:10.4141/P96-078

Medeiros, J.C., Cooper, M., Rosa, J.D., Grimaldi, M., Coquet, Y. (2014) Assessment of pedotransfer functions for estimating soil water retention curves for the amazon region. Rev. Bras. Ci. Solo, 38:730-743. doi:10.1590/S0100-06832014000300005

Mitchell, A.R., Ellsworth, T.R., Meek, B.D. (1995) Effect of root systems on preferential flow in swelling soil. Commun. Soil Sci. Plant Anal., 26:2655-2666. doi:10.1080/00103629509369475

Moebius-Clune, B.N., Moebius-Clune, D.J., Gugino, B.K., Idowu, O.J., Schindelbeck, R.R., Ristow, A.J., van Es, H.M., Thies, J.E., Shayler, H.A., McBride, M.B., Kurtz, K.S.M., Wolfe, D.W., Abawi, G.S. (2016) Comprehensive Assessment of Soil Health. The Cornell Framework 3, Cornell University, Geneva.

Monnier, G., Stengel, P., Fies, J.C. (1973) Une methode de mesure de la densite apparente de petits agglomerats terreux - Application a l'analyse des systemes de porosite du sol. Annales Agronomiques, 24:533-545.

Moraes, M.T., Debiasi, H., Carlesso, R., Franchini, J.C., Silva, V.R., Luz, F.B. (2016) Soil physical quality on tillage and cropping systems after two decades in the subtropical region of Brazil. Soil Till. Res., 155:351-362. doi:10.1016/j.still.2015.07.015

Morel, J.L., Habib, L., Plantureux, S., Guckert, A. (1991) Influence of maize root mucilage on soil aggregate stability. Plant and Soil, 136:111-119. doi:10.1007/BF02465226

Mualem, Y. (1976) A new model for predicting the hydraulic conductivity of unsaturated porous media. Water Resour. Res., 12:513-522. doi:10.1029/WR012i003p00513 
Nascente, A.S., Crusciol, C.A.C., Cobucci, T. (2013) The no-tillage system and cover crops Alternatives to increase upland rice yields. Europ. J. Agronomy, 45:124-131. doi:10.1016/j.eja.2012.09.004

Nunes, M.R., Silva, A.P., Denardin, J.E., Giarola, N.F.B., Vaz, C.M.P., van Es, H.M., Silva, A.R. (2017) Soil chemical management drives structural degradation of Oxisols under a no-till cropping system. Soil Res., 55:819-831. doi:10.1071/SR17063

Nunes, M.R., van Es, H.M., Schindelbeck, R., Ristow, A.J., Ryan, M. (2018) No-till and cropping system diversification improve soil health and crop yield. Geoderma, 328:30-43. doi:10.1016/j.geoderma.2018.04.031

Oades, J.M., Waters, A.G. (1991) Aggregate hierarchy in soils. Aust. J. Soil Res., 29:815-828. doi:10.1071/SR9910815

Obour, P.B., Jensen, J.L., Lamandé, M., Watts, C.W., Munkholm, L.J. (2018) Soil organic matter widens the range of water contents for tillage. Soil Till. Res., 182:57-65. doi:10.1016/j.still.2018.05.001

Osunbitan, J.A., Oyedele, D.J., Adekalu, K.O. (2005) Tillage effects on bulk density, hydraulic conductivity and strength of a loamy sand soil in southwestern Nigeria. Soil Till. Res., 82:5764. doi:10.1016/j.still.2004.05.007

Pimentel, D., Harvey, C., Resosudarmo, P., Sinclair, K., Kurz, D., McNair, M., Crist, S., Shpritz, L., Fitton, L., Saffouri, R., Blair, R. (1995) Environmental and economic costs of soil erosion and conservation benefits. Science, 267:1117-1123. doi:10.1126/science.267.5201.1117

Pires, L.F., Borges, J.A.R., Rosa, J.A., Cooper, M., Heck, R.J., Passoni, S., Roque, W.L. (2017) Soil structure changes induced by tillage systems. Soil Till. Res., 165:66-79. doi:10.1016/j.still.2016.07.010

Rabot, E., Wiesmeier, M., Schlüter, S., Vogel, H.-J. (2018) Soil structure as an indicator of soil functions: A review. Geoderma, 314:122-137. doi:10.1016/j.geoderma.2017.11.009

Rasse, D.P., Smucker, A.J.M., Santos, D. (2000) Alfalfa root and shoot mulching effects on soil hydraulic properties and aggregation. Soil Sci. Soc. Am. J., 64:725-731. doi:10.2136/sssaj2000.642725x

Rawls, W.J., Pachepsky, Y.A., Ritchie, J.C., Sobecki, T.M., Bloodworth, H. (2003) Effect of soil organic carbon on soil water retention. Geoderma, 116:61-76. doi:10.1016/S00167061(03)00094-6

Richard, G., Cousin, I., Sillon, J.F., Bruand, A., Guérif, J. (2001) Effect of compaction on the porosity of a silty soil: Influence on unsaturated hydraulic properties. Europ. J. Soil Sci., 52:49-58. doi:10.1046/j.1365-2389.2001.00357.x 
Santos, H.G., Jacomine, P.K.T., Anjos, L.H.C., Oliveira, V.A., Lumbreras, J.F., Coelho, M.R., Almeida, J.A., Araújo Filho, J.C., Oliveira, J.B., Cunha, T.J.F. (2018) Sistema Brasileiro de Classificação de Solos. 5.ed. Embrapa, Brasília. 356p.

Schlüter, S., Großmann, C., Diel, J., Wu, G.-M., Tischer, S., Deubel, A., Rücknagel, J. (2018) Long-term effects of conventional and reduced tillage on soil structure, soil ecological and soil hydraulic properties. Geoderma, 332:10-19. doi:10.1016/j.geoderma.2018.07.001

Silva, A.P., Kay, B.D., Perfect, E. (1994) Characterization of the least limiting water range of soils. Soil Sci. Soc. Am. J., 58:1775-1781. doi:10.2136/sssaj1994.03615995005800060028x

Silva, R.B., Lanças, K.P., Miranda, E.E.V., Silva, F.A.M., Baio, F.H.R. (2009) Estimation and evaluation of dynamic properties as indicators of changes on soil structure in sugarcane fields of Sao Paulo State - Brazil. Soil Till. Res., 103:265-270. doi:10.1016/j.still.2008.10.018

Skaalsveen, K., Ingram, J., Clarke, L.E. (2019) The effect of no-till farming on the soil functions of water purification and retention in north-western Europe: A literature review. Soil Till. Res., 189:98-109. doi:10.1016/j.still.2019.01.004

Strudley, M.W., Green, T.R., Ascough II, J.C. (2008) Tillage effects on soil hydraulic properties in space and time: State of the science. Soil Till. Res., 99:4-48. doi:10.1016/j.still.2008.01.007

Swinton, S.M., Lupi, F., Robertson, G.P., Landis, D.A. (2006) Ecosystem services from agriculture: Looking beyond the usual suspects. Amer. J. Agr. Econ., 88:1160-1166. doi:10.1111/j.1467-8276.2006.00927.x

Teixeira, R.A., Soares, T.G., Fernandes, A.R., Braz, A.M.S. (2014) Grasses and legumes as cover crop in no-tillage system in northeastern Pará Brazil. Acta Amazonica, 44:411-418. doi:10.1590/1809-4392201305364

Tisdall, J.M., Oades, J.M. (1982) Organic matter and water-stable aggregates in soils. J. Soil Sci., 33:141-163. doi:10.1111/j.1365-2389.1982.tb01755.x

Tormena, C.A., Roloff, G., Sá, J.C.M. (1998) Propriedades físicas do solo sob plantio direto influenciadas por calagem, preparo inicial e tráfego. Rev. Bras. Ci. Solo, 22:301-309. doi:10.1590/S0100-06831998000200016

Tormena, C.A., Silva, A.P., Libardi, P.L. (1999) Soil physical quality of a Brazilian Oxisol under two tillage systems using the least limiting water range approach. Soil Till. Res., 52:223-232. doi:10.1016/S0167-1987(99)00086-0

Triplett, G.B., Dick, W.A. (2008) No-tillage crop production: A revolution in agriculture! Agronomy J., 100:153-165. doi:10.2134/agronj2007.0005c

USDA - United Service Department of Agriculture. (1996) Soil Conservation Service. Soil Survey Investigations Report No.1. USDA, Whashington. 63p. 
van Genuchten, M.Th. (1980) Closed-form equation for predicting the hydraulic conductivity of unsaturated soils. Soil Sci. Soc. Am. J., 44:892-898. doi:10.2136/sssaj1980.03615995004400050002x

Vanwalleghem, T., Gómez, J.A., Amate, J.I., Molina, M.G., Vanderlinden, K., Guzmán, G., Laguna, A., Giráldez (2017) Impact of historical land use and soil management change on soil erosion and agricultural sustainability during the Anthropocene. Anthropocene, 17:13- 29. doi:10.1016/j.ancene.2017.01.002

Veihmeyer, F.J., Hendrickson, A.H. (1949) Methods of measuring field capacity and permanent wilting percentage of soils. Soil Sci., 68:75-94.

Vezzani, F.M., Mielniczuk, J. (2009) Uma visão sobre qualidade do solo. Rev. Bras. Ci. Solo, 33:743-755. doi:10.1590/S0100-06832009000400001

Villamil, M.B., Bollero, G.A., Darmody, R.G., Simmons, F.W., Bullock, D.G. (2006) No-till corn/soybean systems including winter cover crops: Effects on soil properties. Soil Sci. Soc. Am. J., 70:1936-1944. doi:10.2136/sssaj2005.0350

Wander, M.M., Traina, S.J., Stinner, B.R., Peters, S.E. (1994) Organic and conventional management effects on biologically active soil organic matter pools. Soil Sci. Soc. Am. J., 58:1130-1139. doi:10.2136/sssaj1994.03615995005800040018x

Watts, C.W., Dexter, A.R. (1996) Structural stability of two Romanian soils as influenced by management practices. Land Degrad. Develop., 7:217-238. dio:10.1002/(SICI)1099145X(199609) 7:3<217::AID-LDR226>3.0.CO;2-B

Wildenschild, D., Hopmans, J.W., Vaz, C.M.P., Rivers, M.L., Rikard, D., Christensen, B.S.B. (2002) Using X-ray computed tomography in hydrology: Systems, resolutions, and limitations. J. Hydrology, 267:285-297. doi:10.1016/S0022-1694(02)00157-9

Yang, X., You, X. (2013) Estimating parameters of van genuchten model for soil water retention curve by intelligent algorithms. Appl. Math. Inf. Sci., 7:1977-1983. doi:10.12785/amis/070537 